\title{
Soft parallel manipulator fabricated by additive manufacturing
}

S. Sunjai Nakshatharan, Jose Gabriel Martinez Gil, Andres Punning, Alvo Aabloo and Edwin Jager

The self-archived postprint version of this journal article is available at Linköping University Institutional Repository (DiVA):

http://urn.kb.se/resolve?urn=urn:nbn:se:liu:diva-163017

N.B.: When citing this work, cite the original publication.

Nakshatharan, S. S., Martinez Gil, J. G., Punning, A., Aabloo, A., Jager, E., (2020), Soft parallel manipulator fabricated by additive manufacturing, Sensors and actuators. B, Chemical, 305, 127355. https://doi.org/10.1016/j.snb.2019.127355

Original publication available at:

https://doi.org/10.1016/j.snb.2019.127355

Copyright: Elsevier

http://www.elsevier.com/

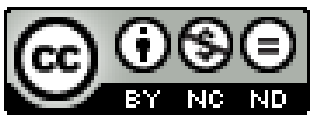




\title{
Soft parallel manipulator fabricated by additive manufacturing
}

\author{
S Sunjai Nakshatharan ${ }^{1,2}$, Jose G Martinez ${ }^{1}$, Andres Punning ${ }^{2}$, Alvo Aabloo² ${ }^{2}$ Edwin W.H. Jager ${ }^{1}$ \\ ${ }^{1}$ Division of Sensor and Actuator Systems, Department of Physics, Chemistry and Biology (IFM), \\ Linköping University, SE-581 83, Linköping, Sweden \\ ${ }^{2}$ Intelligent Materials and Systems Laboratory, Institute of Technology, University of Tartu, Estonia
}

\begin{abstract}
:
Conducting polymer (CP) based soft actuators are good candidates for miniaturised manipulation systems and soft robotic applications. We present the fabrication, characterization, and modelling, of a novel ionically driven soft, flat, parallel manipulator with minimal footprint actuated by CP actuators. This three degrees of freedom (3Dof) manipulator consists of four trilayer actuators with poly (3, 4- ethylenedioxythiophene):poly(styrene sulfonate) (PEDOT:PSS) electrodes on both sides of PVDF separator membrane with 1-Ethyl-3-methylimidazoliummethyl imidazolium bis(trifluoromethylsulfonyl)imide ionic liquid used as the electrolyte. The complete manipulator is fabricated as a monolithic structure using commercially available off the shelf materials by additive manufacturing technique including a syringe type printer. Its workspace and dynamics are characterised and the results are compared with a multiphysics model based on the finite element method. The model uses two types of charge storage mechanism namely electrical double layer and redox reactions to describe the electrode kinetics. Through simulation the charge contributed by each of the processes is separated and presented providing new insights in the underlying kinetics in this type of actuators. It is found the double layer charge is the dominant phenomenon driving these actuators compared to the redox process. Finally, to demonstrate the versatile applications, the manipulator is explored for a four-way laser steering application. This work has demonstrated high levels of manipulability along three degrees of freedom from the printed CP actuators that are outstanding within the class of soft ionic actuators while using off the shelf commercially available materials keeping the fabrication method simple, scalable and cost-effective along with the electro-chemo-mechanical model providing insight view of charge storage mechanism.
\end{abstract}

Keywords: Soft actuator; 3D printing; PEDOT:PSS; Parallel manipulator; Modelling

\section{Introduction}

Electroactive polymer materials based on conducting polymers have been regarded as promising candidates for soft actuators in soft robotic applications due to their characteristic features such as the requirement of 
the low driving voltage, large deformation, lightweight, flexible and noiseless operations [1]. The primary factor leading to the actuation of the material is a volume change accompanied by the ion ingress and egress into and out of the polymer matrix and electrolyte solution [2,3].

Common deposition techniques for conducting polymer used in the fabrication of ionic soft actuators include direct electrochemical synthesis [4,5], spin coating [6] and drop-casting [7,8]. For the fabrication of microdevices and lab on a chip applications, these techniques are combined with microfabrication and photolithography techniques [3,9]. However, this requires a clean room facility and is also both a timeconsuming and expensive approach. Recently inkjet and syringe-based printing of conducting polymer actuators have been reported [10-13]. Compared to cleanroom fabrication, these printing techniques are low cost, high speed, and have high precision and it can be used in linear arrays for high throughput fabrication. Furthermore, it allows the use of several materials in parallel that could be employed in the one-step fabrication of the actuators and sensors [12]. Another interesting method to deposit conducting polymers is additive manufacturing, often addressed as 3D printing. The basic principle of additive manufacturing is based on the building an object by adding material (layer-by-layer) to replicate a digital 3D model. There are several 3D printing methods such as melting materials, often from powder beds, by sintering [14], polymerizing materials with laser-or UV-light (stereolithography or SLA-printing) [15] and adding material by melt extrusion (fused deposition modelling, FDM) [16,17]. The extrusion-based 3D printers add material bottom-up to an object. Thermoplastic printers are the most common printers used to extrude plastic filament heated to $80^{\circ} \mathrm{C}$ or more, but the elevated temperature excludes the use of materials that are easily destroyed at these temperatures, including conducting polymers and biological materials [18]. Recently, SLA printing has been used to 3D print polypyrrole but this method required special pyrrole formulations and the electromechanical activity of the material has not been demonstrated [19]. Another type of additive deposition tool is the inkjet printer, which uses a deposition head like those commonly found in commercial desktop printers and can be used to print conducting polymers and specifically Poly (3, 4-ethylenedioxythiophene): poly (styrenesulfonic acid) (PEDOT:PSS).

Among several conducting polymer PEDOT:PSS is considered as one of most successful and is widely available commercially owing to its high conductivity, high specific capacitance, easily solutionprocessable and have excellent thermal and chemical stability [20,21]. Printing of PEDOT:PSS is extensively studied for manufacturing flexible electronics and solar cells [22,23]. Compared to polyelectrolyte gels which lack mechanical strength and prone to leakage of solvent [24], PEDOT:PSS offers superior performance for actuator application. However, printing PEDOT:PSS actuators with a commercially available inkjet nozzle is highly challenging since it requires appropriate viscosity, density and surface tension [23,25] and to solve issues involving low solubility and miscibility of conducting polymers. Various additives are often needed in order to adjust rheological properties of the ink to suit for 
printing using an inkjet nozzle $[12,26]$. On the other hand, using low-cost custom printing based on syringetype systems provides much freedom in terms of the use of various materials and the possibility to modify the printer parameters to suit specific applications [27]. Syringe-based printers can extrude both high and low viscosity materials [9] and are used to print different materials such as silicones, biomaterials including cells, frosting, and conducting polymers [28-31]. These types of printer use a bottom-up manufacturing technique where the material is added layer-by-layer on a substrate or device and can achieve geometric structures difficult or impossible to produce with more traditional manufacturing techniques. This method allows easy fabrication of soft robotic devices using commercially available off the shelf materials with limited or no need for chemical processing [27].

In this work, we present additive manufacturing and modelling of a parallel manipulator made out of a single monolithic structure printed with a syringe-type system using commercially available off-the-shelf materials. The proposed system can produce three degrees of motion that include linear displacement along one axis and rotational along two axes. The manipulator consists of four trilayer actuators with PEDOT:PSS electrodes supporting a square-shaped central platform at the vertices. Trilayer actuators are composed by a passive layer/membrane sandwiched between two active CP layers. One of the active CP layers acts as anode, attracting and incorporating cations (thus swelling) while the other one acts as cathode repelling and expelling cations (thus shrinking). Thus, when one layer swells, it pushes the trilayer while the other shrinks and pulls it, thus generating a bending motion as shown in Figure 1(a). When the polarity is reversed, the ion flows are reversed and the trilayer actuator bends in the opposite direction. When the passive layer/membrane is filled by ions, for example by filling it with an ionic liquid, it functions as an ion reservoir and allows to be actuated outside a liquid electrolyte [26,32,33]. Here we combine four trilayer actuators can be actuated individually or simultaneously in order to move the platform in a desired orientation and position. The proposed design and the different degree of motion produced by the mechanism are shown in Figure 1(b and c) and the connecting points of the platform and the actuators are denoted by numbers $(1,2$, 3 and 4). The manipulator proposed has the main advantage that it is fabricated as a single structure and it does not require any additional support mechanism or linkage to obtain the different degree of motion. Such a soft monolithic body is the aim of the emerging field of biologically inspired robotics or soft robotics system [34].

These ionic electroactive actuators with manipulation capability in one or two axes open a wide range of applications in several fields. Two ring-shaped Ionic polymer-metal composite (IPMC) cantilever beams based micromirror developed by Yun et al. [35] generated $0.25 \mathrm{~mm}$ linear displacement and the maximum tilting angle of $\pm 11.3^{\circ}$ on one axis at an input voltage of $4 \mathrm{~V}$. The circular mirror with three actuators designed by Tsai et al. [36] generated maximum displacement of $45 \mu \mathrm{m}$ and $77.8 \mathrm{~m}^{-1}$ optical power change, which is a change in the reciprocal of the focal length of the device. The IPMC mirror based compact 
camera optical zoom module developed by Chen et al. [37] attained a maximum displacement of $200 \mu \mathrm{m}$ and was able to change the optical power to $73.8 \mathrm{~m}^{-1}$. With reference to linear actuating stages, microscope stage mechanism with three polypyrrole actuator designed by Mutlu et al.[34] generated $1 \mathrm{~mm}$ displacement at $1 \mathrm{~V}$. The four IPMC actuator configuration with a flexible connector developed by Yamakita et al. [38] generates a maximum displacement of $10 \mathrm{~mm}$ at $2.5 \mathrm{~V}$. The linear actuator using carbon-based electrodes for a mirror application developed by Torop et al. [39] was able to generate a stroke of $15 \mu \mathrm{m}$ at $3 \mathrm{~V}$ along the lateral direction. Using a carbon-polymer composite soft actuator we previously made a manipulator with the same design as proposed in this work which was able to generate large stoke of $15 \mathrm{~mm}$ and rotational angle of $\pm 15^{\circ}$, but the system is very slow with a rise time of $18 \mathrm{~s}$ to reach $90 \%$ of the maximum displacement and also it requires a complex manufacturing technique which is labour intensive [40].

The goal of this paper is to present a 3D printed parallel manipulator that can generate large stroke and rotation angles and generate three degrees of motion in a monolithic configuration that can be easily manufactured and uses commercially available off the shelf materials. Further, we present a finite element method (FEM) based Multiphysics model to describe the electro chemo mechanical dynamics of the printed actuators and it is proposed that the underlying electrochemical kinetics is contributed by two different phenomena namely electric double layer charging/discharging and redox reactions. In electric double layer charging and discharging process, there is no electrochemical reaction and there is only accumulation of charge at the electrode/electrolyte interface whereas in faradic reaction the charge takes part in the oxidation or reduction reactions of the polymer [41]. There are attempts to improve the actuation by using both processes by combining electrochemically active PEDOT:PSS and inactive components such as carbonbased materials together in electrode preparation [41,42]. Physically it is rather complicated to measure or separate the charge contributed by each of the processes but through simulation, we separate and provide the charge contribution by each process providing new insights in the underlying kinetics in the PEDOT:PSS printed actuators fabricated in this work. It is found that the double layer charge contributes the most charge and is the dominant phenomenon driving these actuators rather than redox process. Finally, to demonstrate the various application opportunities, a four-way optical switch as an application is explored. 

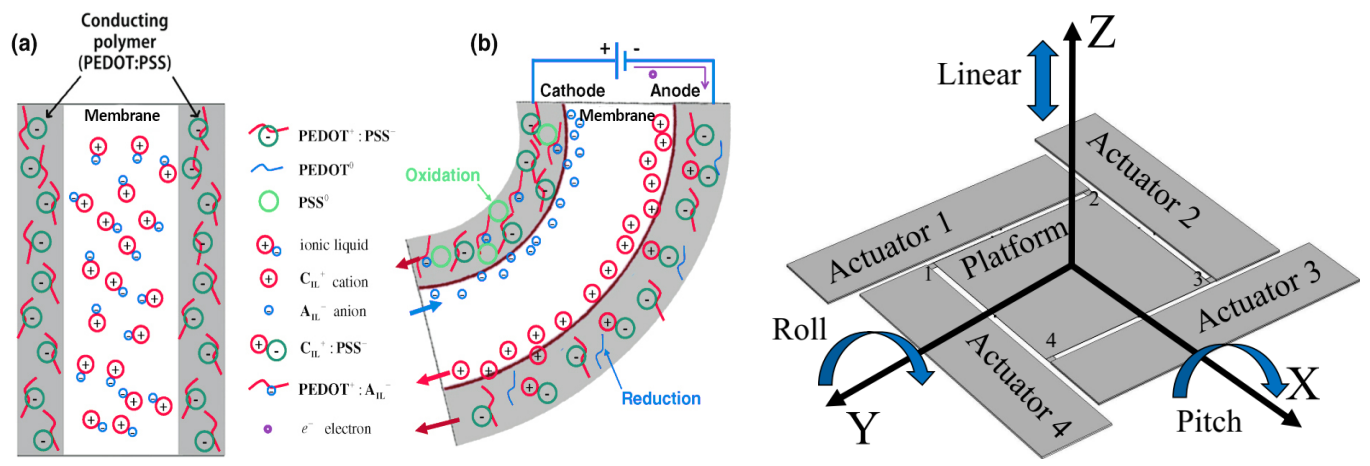

(c)

Fig. 1. Graphical representation CP actuation (a) Actuator in steady-state (b) Under applied voltage Adapted from [43] (c) Proposed configuration of the 3Dof monolithically integrated manipulator comprising four actuators connected with the moving platform at the vertices 1-4 and its three degrees of freedom.

\section{Material and Methods}

\subsection{Fabrication}

The ionic manipulator is fabricated using printing/additive manufacturing where the actuator is built by adding layer-by-layer to replicate a digital 3D-model. The printer and its schematics are shown in figure 2(a) and 2(b). For the current work, the digital 3D model is designed using Solidworks (Dassault Systems), and Seraph studio software is used as a slicer tool to generate g-code instruction for the printer. The 3D printer used in this work is Fab@Home Model 3, from Seraph Robotics Inc [44]. The build volume of the printer is $230 \mathrm{~mm} \times 128 \mathrm{~mm} \times 200 \mathrm{~mm}$ and the positioning accuracy is $100 \mu \mathrm{m}$ with a maximum translational speed of $80 \mathrm{~mm} / \mathrm{s}$. The printer can accommodate a maximum of two reservoirs of $10 \mathrm{ml}$ syringe acting as a deposition tool and it extrudes material through the nozzle tip attached to the syringe by controlling the pressure of the piston. The nozzle diameter ranges from $0.1 \mathrm{~mm}$ to $1.54 \mathrm{~mm}$. The limits on the size of the printed object depend on the selection of the size of the nozzle, material viscosity, nozzle translation speed, extrusion rate and ambient temperature. These parameters need to be adjusted and optimized to achieve an even, straight structure without any gaps in the printed lines [18]. This freedom in access and optimizing the printing parameters makes the syringe-based printers to extrude both high and low viscosity materials unlike in a typical inkjet printer. 


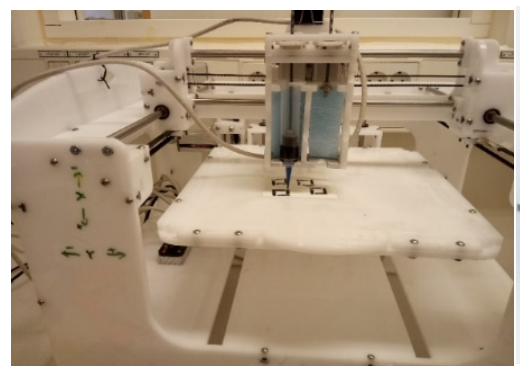

(a)

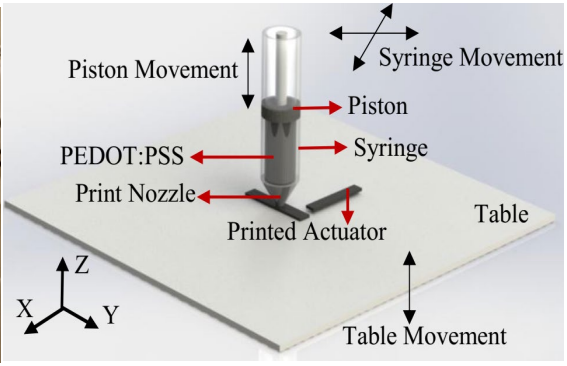

(b)

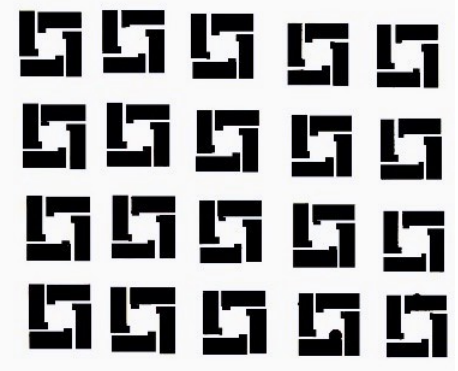

(c)

Fig. 2. (a) A photograph of the 3D Printer (b) Printer Schematics (c) Photograph of a batch of the printed matrix array

For printing the manipulator developed in this work, PEDOT:PSS in aqueous dispersion (Clevios TM PEDOT:PSS ink PH1000, Heraeus GmbH) is used as the electrode material for the actuator segments. In order to increase the conductivity, $5 \% \mathrm{w} / \mathrm{w}$ dimethyl sulfoxide (DMSO) is added [45]. The content was mixed together and stored in the $10 \mathrm{ml}$ syringe with an extraction nozzle diameter of $400 \mu \mathrm{m}$. The deposition tool can translate in the $\mathrm{x}$ and $\mathrm{y}$-directions (horizontal plane) while the material is deposited by the movement of the piston in the syringe. To create multi-layered structures, either the table or the deposition tool can be moved in the z-direction, creating space for depositing the next layer. The rate of deposition is controlled by piston pressure and translation speed and is optimized for this specific PEDOT:PSS. One layer of printed segment results in an electrode thickness of $15 \mu \mathrm{m}$. Using the $400 \mathrm{um}$ nozzle and specified PEDOT:PSS solution the minimum line width printable by the printer is $100 \mu \mathrm{m}$ with $15 \mu \mathrm{m}$ thickness and possible minimum separation between lines is $100 \mu \mathrm{m}$ which is the minimum step resolution of the printer.

PVDF membrane (IPVH00010 by Immobilon) with $125 \mu \mathrm{m}$ thickness is used as the separator membrane onto which the electrodes are printed. The PVDF membrane is hydrophobic in nature affecting the adhesion of PEDOT:PSS on to the surface, and hence in order to improve the adhesion the membrane is oxygen plasma-treated at $200 \mathrm{~W}$ power for $5 \mathrm{~min}$ just before the printing to make the surface hydrophilic on both sides of the membrane. Once one side of the membrane is printed, the electrode is dried at $40^{\circ} \mathrm{C}$ for 6 hours before resuming to print on the other side. 


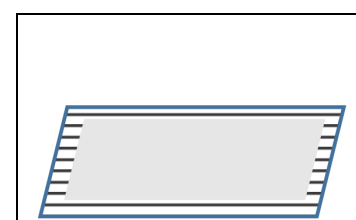

(a) Oxygen plasma treated PVDF

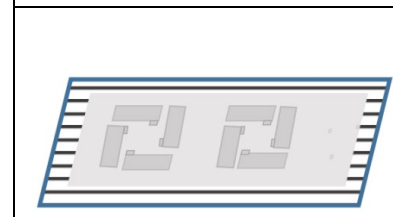

(c) Drying for 6 hours, flip substrate, and aligned on another side

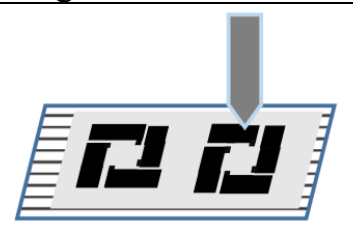

(e) Dropping of ionic liquid

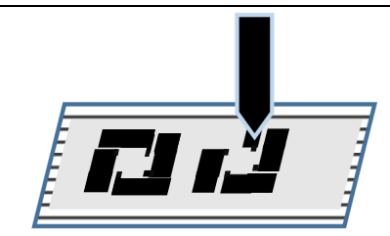

(b) Printing on one side

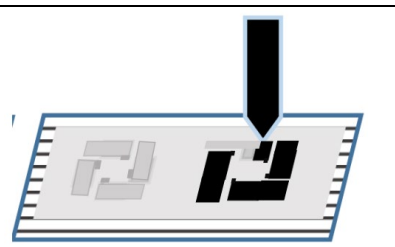

(d) Printing on the other side

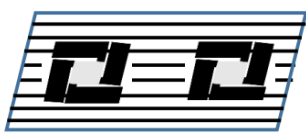

(f) Cutting after 12 hours

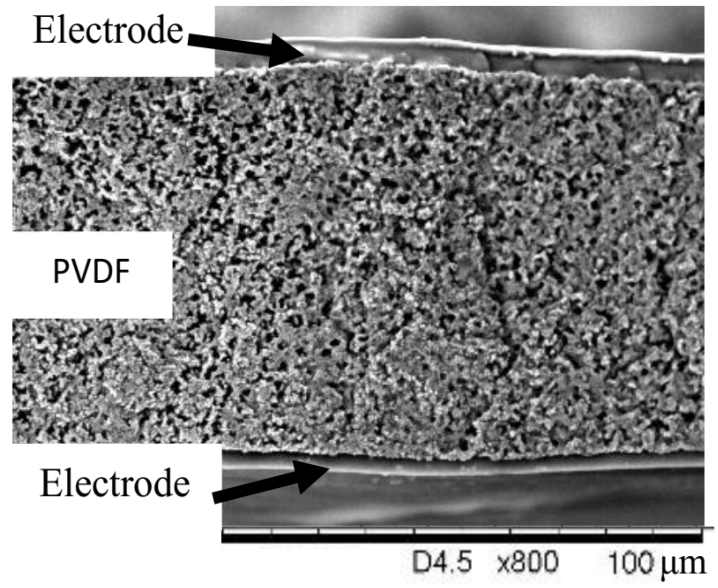

(g)

Fig. 3. (a-f) Sketch of the fabrication process (g) SEM Image of the cross-section of the printed sample

Once the PEDOT:PSS electrodes are printed on both sides of the membrane, 1-Ethyl-3-methylimidazolium bis(trifluoromethylsulfonyl)imide (EMIM-TFSI from Sigma Aldrich) ionic liquid is dropped on top of the printed material and is kept between 2 glass slides for 12 hours. Before characterization, the sample is sliced using a scalpel appropriately removing the unwanted membrane region and thus freeing the actuators and platform resulting in the parallel manipulator. One layer of PEDOT:PSS is printed on both sides of the membrane resulting in electrode thickness of $15 \mu \mathrm{m}$ on each side and the dimension of each actuator is 11 $\mathrm{mm}$ in length and $4 \mathrm{~mm}$ by width. The entire manipulator with the central platform and four actuators are $16 \times 16 \mathrm{~mm}^{2}$. The SEM micrograph image showing the printed actuator cross-section with a single layer of the electrode on both sides of the PVDF membrane is shown in Figure 3(g).

\subsection{Electromechanical Modelling}

Considering modelling of the electroactive polymer actuators there are different methodologies based on different aspects of the working principle. They include bending beam method [46,47] related to the mechanical study of solid state beam bending, equivalent circuit model $[48,49]$ where electrical equivalent circuit is developed giving similar electrical response of the actuator, electrochemical model based on faradic conditions that use a linear relationship between applied current and angular movement $[50,51]$ and 
finite element model $[34,52,53]$. In this work, we provide a physics-based approach using the finite element method where charge transport electrochemical response is coupled with mechanical response caused by volumetric swelling.

The finite element simulations were carried out with COMSOL Multiphysics 5.3 software and compared with the experimental results to verify the developed model. The simulation uses transport of dilute species, solid mechanics and electric currents COMSOL modules to describe the governing equations. The NernstPlanck-Poisson equation is solved by the transport of dilute species module and the concentration gradient solution obtained is coupled to the solid mechanic module for obtaining the deformation. For studying the cyclic voltammetry through simulation COMSOL electroanalysis interface is used. The following assumptions are made while modelling the actuator

1. Temperature effects are negligible

2. There are no influence of porosity and tortuosity effects.

3. No electrochemical side reactions occur in the system

4. All mechanical parameters remain constant

5. No change in the electrode and ionic conductivities during actuation.

\subsection{Mechanical model description}

The electrochemical response resulting in ion transport is followed by mechanical deformations of the actuator. In comparison to previous Multiphysics models coupling Poisson-Nernst-Planck equation with linear elastic theory, the mechanical deformation is related to charge via an experimentally measured coupling constant [54-56]. In this proposed model, bending strain is associated with intercalation of ions resulting in volumetric swelling of the electrodes. The volumetric swelling and shrinkage of the electrodes were experimentally verified by Punning et al. through digital image correlation methodology [47] conducted on IEAP actuators, where the actuators are spatially marked with factual regions and change in the volume is measured before and after the actuation. This model directly relates the solution solved by the PNP equation to the mechanical deformation. Thereby the influence of properties of anions and cations such diffusion coefficient, mobility and viscosity and their effect on deformation and direction of deformation is established.

During ion exchange the total stress $\sigma_{T}$ generated in the material is given by

$\sigma_{T}=\sigma_{M}-\sigma_{\text {in }}$

The volumetric stress $\sigma_{\text {in }}$ acts in the direction opposite to the natural mechanical stress $\sigma_{M}$ of the actuator and is caused by the strain due to swelling of the electrode. Governed by Hooke's law the relation is given 
by

$\sigma_{\text {in }} \alpha \varepsilon_{\text {in }}$

$\sigma_{i n}=E \varepsilon_{i n}$

Where E is the Youngs's Modulus. The Strain $\varepsilon_{i n}$ is proportional to concentration gradient (in both, solution and inside the conducting polymer) obtained solving the electro-chemical model (Eq. 8-15) which follows in section 3.1

$$
\begin{aligned}
& \varepsilon_{\text {in }} \alpha\left(C_{+}-C_{-}\right) \\
& \varepsilon_{\text {in }}=\beta_{s s} M_{s} \Delta C_{d i f f}
\end{aligned}
$$

Where $M_{S}$ is molar mass of the ionic liquid and $\beta_{S S}$ is swelling coefficient relating strain and ion concentration. The swelling coefficient is used as a tuning parameter to match the experimental and simulation results. Youngs's Modulus is measured using the three-point bending method [57]. The parameters used for simulation is shown in Table 1. The comparison between the experimental and simulation results are discussed in the later section. The simulation results of the electromechanical response of the printed manipulator and the comparison with experimental characterization are discussed in section 3.4 .

\subsection{Mechanical characterization setup for manipulator}

Experiments are conducted to characterize and analyse the workspace (displacement and rotation angle) of the printed parallel manipulator. Each of the actuators can act independently and hence the platform can achieve a wide range of rotational as well as linear movements within the spherical workspace. A $2 \mathrm{~V}$ step signal is applied to each of the actuators to measure the displacement and rotation movements. The positive polarity of the input voltage causes the actuator to move up along the Z-axis and the negative polarity causes downward motion, with a different combination of the polarity to each of the actuator, the platform can be made to manipulate over a different axis. To measure the three degrees of freedom motion of the platform at least three position sensors (from which equation of a plane can be formed) or a stereo camera is required. However, to avoid the complexity and expensive use of sensors a simpler method is adopted as shown in figure 4. A gold sputter-coated mirror is fixed on to the platform and is used to steer a laser beam from a laser displacement sensor (LG10A65PU) on to a calibrated measurement scale. The reflected light is used to calculate the rotational angles using the Eq. 6 derived from the figure using trigonometric rules. The schematic arrangement of the experimental setup is shown in figure 4a. To measure the linear motion the laser displacement sensor is used directly without the mirror. 
$\theta=\sin ^{-1}\left(\frac{\mathrm{L} 1}{\mathrm{H} 1}\right)=\sin ^{-1}\left(\frac{\mathrm{L} 1}{\sqrt{\mathrm{L}^{2}+\mathrm{L} 1^{2}}}\right)$

where $\mathrm{L} 1$ is the distance travelled by the laser point from the stationary position of the platform under zero potential to the new position after actuation and $\mathrm{L}$ is the known distance between platform arrangement and the scale. $\theta$ is the angle generated by the platform by moving the laser point over the distance L1. H1 is the distance between the platform and the new laser point position. Using trigonometric rules, the angle made by the platform is given by Eq.6. Similary during rotation in the opposite direction the angle is determined using the values of L2 and H2. The sensor data is collected using National Instruments PCI 6703E via an SC-2345 connector module. The actuators are driven via a National Instruments PCI 6703 data acquisition card and amplified by power op-amplifier LM675T via a NI SCB-68 connector module. For blocking force measurement, force transducer MLT0202 from AD Instruments with the measurement range $0-0.245 \mathrm{~N}$ is used. A computer running MATLAB controls the input and output through the sensors and actuators.

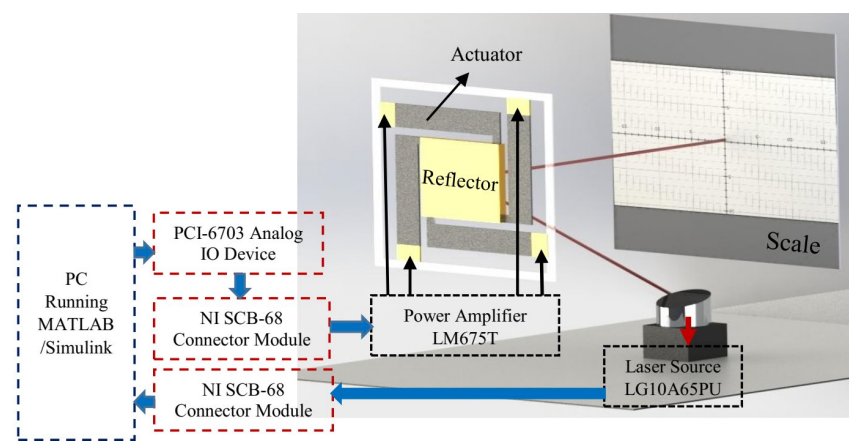

(a)

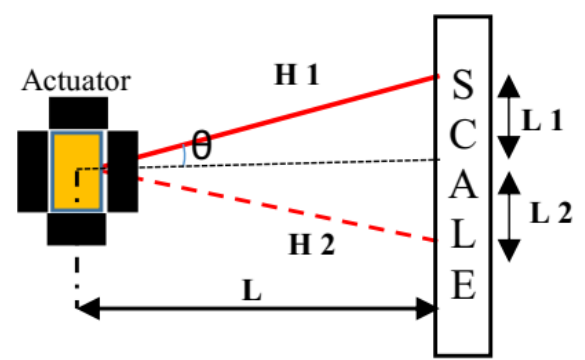

(b)

Fig. 4. (a) Schematics of the experimental setup with input/output DAQ channels connected to the actuator and platform reflecting light on to the scale (b) Angle measurement schematics with laser light reflected on the scale at a rotational angle of $\theta$.

\section{Results and discussion}

\subsection{Electrochemical model description}

Cyclic voltammetry measurements are conducted on the printed actuator and the results are shown in Figure 5. In the potential range of -1.0 to $1.0 \mathrm{~V}$ the actuator exhibits a characteristic rectangular shape representing the electrochemical signature of a capacitive electrode due to electrical double-layer formation [58] along with the electrode/electrolyte interface. In the potential range $\pm 2 \mathrm{~V}$ and above, in addition to the double layer, the actuator exhibits an accompanied reversible redox reaction seen through the occurrence of redox peaks. When PEDOT is reduced to its neutral state, the cations are inserted into the polymer matrix in order to compensate for the charge imbalance and the process is reversed during oxidation where the cations that 
compensated for the PSS polyanions are ejected from the polymer matrix resulting in volume change causing actuation [59]. This process of charging results in capacitance. The calculated capacitance of the printed actuators in ionic liquid solution from the $\mathrm{CV}$ is $154.58 \mathrm{~F} / \mathrm{g}$ using the formula [60]

$C=\frac{\oint i_{\text {total }}(V) d V}{2 * v *\left(V_{\max }-V_{\min }\right) * m}$

Here $C$ is the capacitance and $\oint i_{\text {total }}(V) d V$ is the total volumetric charge contributed by the different kinetics, $\left(V_{\max }-V_{\min }\right)$ is the potential window, $m$ is the mass of the sample and $v$ is the scan rate. Similar values are previously reported for the printed PEDOT:PSS based electrodes [10,61].

Considering the actuation of the conducting polymer actuators it is generally accepted that the charge storage mechanism is mainly due to redox reactions [9,10,61-64]. However, the proposed model in this work considers the charge storage and subsequent actuation is due to both the redox reactions as well as electric double layer capacitance charging/discharging. Experimentally it is complicated to separate the process to determine the charge contributed by the each of the processes [65], but through simulation (by deconvolution), the model proposed here can separate each process and provides insights into the underlying mechanisms and thus provide the charge contribution made by the completely different kinetics. The model uses the Butler-Volmer equation [66] to represent the faradaic current due to redox reactions and the current plateaus representing double layer charging effect are described using phenomenological double layer capacitive relation exhibiting a linear dependence of the charge stored with the width of the potential window $[58,67,68]$. Previously we have reported multiphysics modelling of coupling electrochemical and mechanical response for carbon-based actuator ionic actuators [69], with purely capacitive behaviour taken into consideration and here the model is modified to also include the redox behaviour.

Considering the challenging task of modelling the manipulator due to the mechanical topology and involvement of multidomain properties (chemical, electrical and mechanical), the model proposed in this work solves ion transport through the PVDF membrane process with Poisson-Nernst-Plank equation coupled with bending deformation described using linear elastic theory. On applying the potential to the actuator, there is the flow of flux described using the Poisson-Nernst-Planck equation as given in Eq. 8.

$\overrightarrow{J_{l}}=-D_{i} \vec{\nabla} c_{i}-\frac{z_{i} F}{R T} D_{i} c_{i} \vec{\nabla} \Phi_{2},(i=+,-)$

Here $J_{i}, D_{i}, c_{i}$, and $\Phi_{2}$, represents ion flux, diffusion coefficient, concentration of the ions, and potential at electrolyte respectively. The subscript $i$ corresponds to ionic species either cations or anions. The constants $Z, F, R$ and $T$ represent number of charges per ion, Faraday constant $\left(\mathrm{F}=96485 \mathrm{C} \mathrm{mol}^{-1}\right)$, gas 
constant $\left(\mathrm{R}=8.314 \mathrm{~J} \mathrm{~K}^{-1} \mathrm{~mol}^{-1}\right)$ and temperature $(293.15 \mathrm{~K})$ respectively. The initial concentration of ions are measured by measuring the weight of ionic liquid on the sample followed by calculating number of moles on the sample specification. On the application of potential cause a rise to the electronic current $i_{1}$ in the electrode phase and electro-chemical processes both electric double layer and redox reactions causes ionic current $i_{2}$ in the electrode as well as polymer and is given in equation Eq.9 and Eq.10.

$i_{1}=-\rho_{e} \nabla \Phi_{1}$

Here $\rho_{e}$ is the electrode conductivity and $\Phi_{1}$ is the potential at the electrodes.

From Eq. 3, the ionic current can be derived [69] and is given by

$i_{2}=-\rho_{b} \nabla \Phi_{2}-z_{i} F\left(D_{+}-D_{-}\right) \nabla c_{i}$

Here $\rho_{b}$ is the conductivity of the electrolyte. The electrode resistance and electrolyte resistance values are calculated using the Nyquist plot from impedance spectroscopy experiment [70]. From the cyclic voltammetry results, it can be seen there exists characteristics behaviour of electric double layer charging/discharging and redox peaks. Hence due to the electrode kinetics there arise two currents; one due the capacitive process and the other due to the faradic process. The current contributed by electric double layer charge [71,72] is given in Eq. 11 stating the linear dependence of the charge with changing potential representing the typical electrochemical signature of a capacitive electrode. The faradaic current due to redox reactions can be represented using the Butler-Volmer electrochemical kinetic expression [72] given in Eq. 12. The respective double layer current and faradic current are denoted as $i_{d l}$ and $i_{f}$ respectively,

$i_{d l}=C \frac{\partial\left(\Phi_{1}-\Phi_{2}\right)}{\partial t}$

$i_{f}=i_{0}\left(e^{\frac{\alpha_{a} F \eta}{R T}}-e^{\frac{-\alpha_{c} F \eta}{R T}}\right)$

where $C$ corresponds to specific capacitance, $i_{0}$ is exchange current density, $\alpha_{a}$ and $\alpha_{c}$ are the anodic and cathodic rate transfer coefficients. The values $\alpha_{a}$ and $\alpha_{c}$ are 0.5 respectively [50] and the exchange current density is calculated from the Tafel plot [73] and $\eta$ is the activation overpotential [74].

The overall charge balance under the assumption of electroneutrality [75,76] is given by Eq. 13, stating that the divergence of the total current density in the system is zero.

$\nabla \cdot i_{1}+\nabla \cdot i_{2}=0$

At the interface between the electrode matrix and the separator, the rate of change of current $[71,72]$ is given by 
$\nabla i_{2}=C \frac{\partial\left(\Phi_{1}-\Phi_{2}\right)}{\partial t}+i_{0}\left(e^{\frac{\alpha_{a} F \eta}{R T}}-e^{\frac{-\alpha_{c} F \eta}{R T}}\right)$

Finally, the material balance of the electrolyte gives rise to the mass conservation equation

$$
\frac{\partial c_{i}}{\partial t}+\nabla j_{i}=\frac{i_{f}+i_{d l}}{F * z_{i}}
$$

where $\frac{i_{f}+i_{d l}}{F * z_{i}}=R_{i}$ is the reaction rate representing a source or sink term in the material balance equation.

To understand electrochemical charge storage mechanism cyclic voltammetry measurements that allow understanding of the different electrochemical processes involved in an easy and more direct way were conducted on the printed trilayer actuator with EMIM-TFSI ionic liquid at a scan rate of $50 \mathrm{mV} \mathrm{s}{ }^{-1}$ with three different potential windows and the results are shown in figure 5. Followed by Cyclic voltammetry analysis using COMSOL Multiphysics at $50 \mathrm{mV} \mathrm{s}^{-1}$ with two different potential windows of $\pm 1 \mathrm{~V}$ and $\pm 2 \mathrm{~V}$ were simulated.

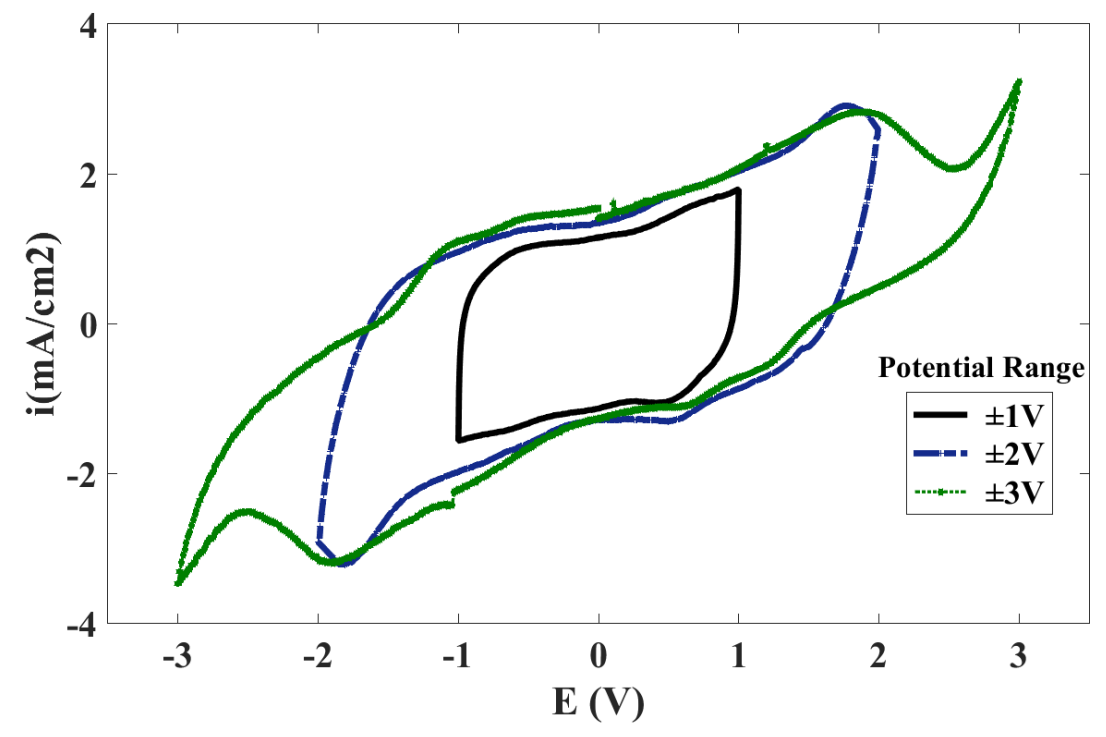

Fig. 5. Cyclic Voltammetry measurement results

\subsection{Electrochemical analysis simulation}

In order to verify the proposed model and to understand the charge contributed by each process, simulation of the actuator was performed. At first, the simulation is performed with both the process taking place simultaneously that includes both Eq.11 and Eq. 12 and subsequent simulations were performed with each process occurring individually (either Eq. 11 or Eq. 12 is active) and other being neglected. Figure 6(a) shows the applied potential at $50 \mathrm{mV} / \mathrm{s}$ with a potential range from -2 to $2 \mathrm{~V}$ and the Figure $6(\mathrm{~b})$ shows the 
current contributed by each of the processes individually as well as the total current contributed by both processes. Figure 6(c) shows the $\mathrm{CV}$ results of simulation of each process compared with the experimental results. It is seen on summing up both processes, that the simulation matches closely with the experimental results representing the redox peak as well as characteristic double-layer capacitance behaviour. The charge contributed by each of the processes is calculated using the Eq. 16

$C=\frac{\oint i_{\text {total }}(V) d V}{2 * v}$

From Figure 6(c), the total charge density calculated through the simulation is $124.29 \mathrm{mC} / \mathrm{cm}^{2}$, the double layer charge and charge contributed from faradic process calculated individually are $105.92 \mathrm{mC} / \mathrm{cm}^{2}$ and $18.372 \mathrm{mC} / \mathrm{cm}^{2}$, respectively. The experimentally calculated charge density is found to be $107.4 \mathrm{mC} / \mathrm{cm}^{2}$. Under the potential window of $\pm 1 \mathrm{~V}$ (Figure 7), the total charge calculated from experimental results is $44.562 \mathrm{mC} / \mathrm{cm}^{2}$ and the simulation values are $48.90 \mathrm{mC} / \mathrm{cm}^{2}$ in which the faradic process and double layer process charge contributions are $2.68 \mathrm{mC} / \mathrm{cm}^{2}$ and $46.22 \mathrm{mC} / \mathrm{cm}^{2}$, respectively.

It is found that double layer capacitance contributes more to the charge storage compared to the redox process in both the potential range of $\pm 2 \mathrm{~V}$ and $\pm 1 \mathrm{~V}$. From the results, it is shown that the double layer process is the most dominated mechanism in these printed actuators.

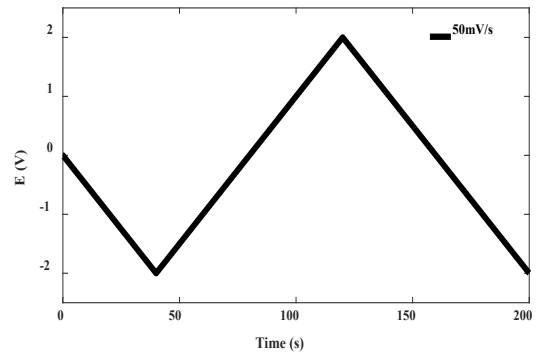

(a)

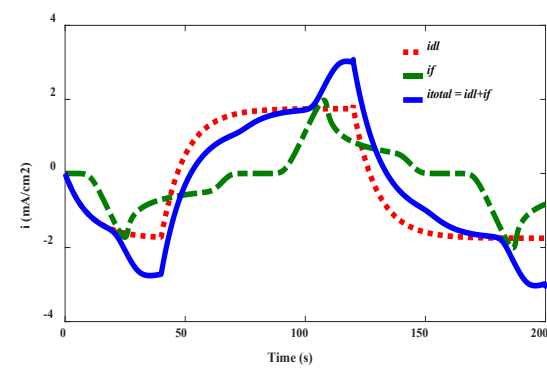

(b)

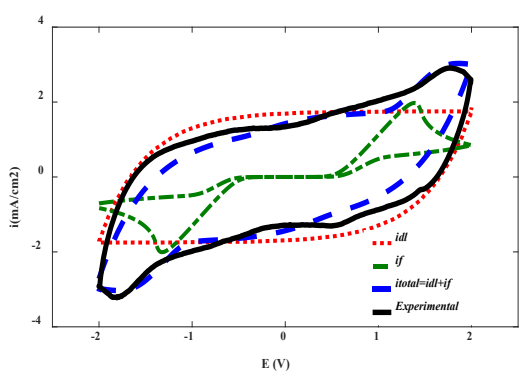

(c)

Fig. 6. (a) $\pm 2 \mathrm{~V}$ applied potential at $50 \mathrm{mV} / \mathrm{s}$ (b) Simulation of current density representing double layer current, faradic current and total current with respect to time (c) Cyclic voltammetry results representing double layer current, faradic current, total current compared with experimental results. 


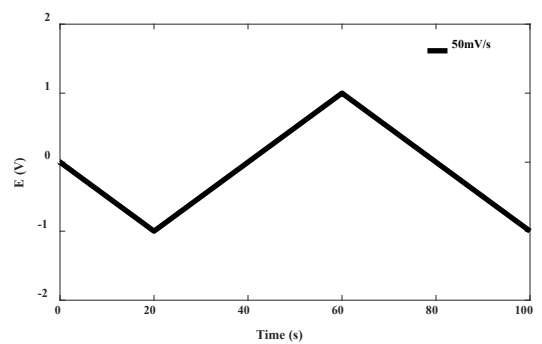

(a)

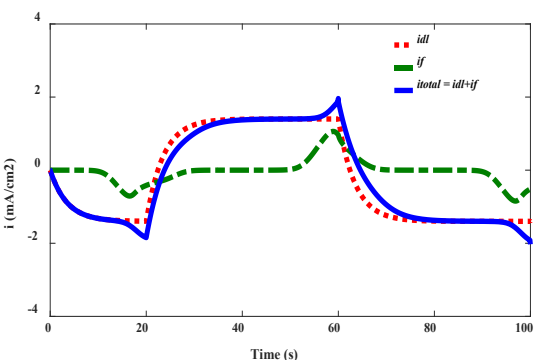

(b)

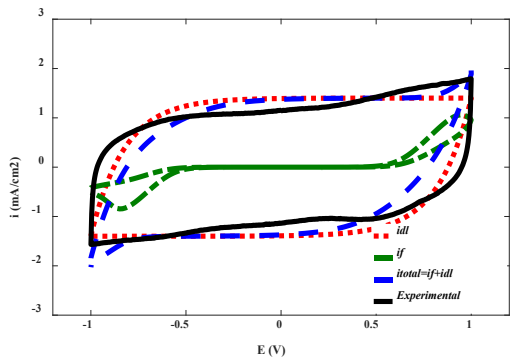

(c)

Fig. 7. (a) $\pm 1 \mathrm{~V}$ applied potential at $50 \mathrm{mV} / \mathrm{s}$ (b) Simulation of current density representing double layer current, faradic current and total current with respect to time (c) Cyclic voltammetry results representing double layer current, faradic current, total current compared with experimental results.

Table 1: Simulation parameters

\begin{tabular}{cllll}
\hline Symbol & Quantity & Value & Units & Reference \\
\hline$L_{e}$ & Electrode thickness & 15 & $\mu \mathrm{m}$ & Measured \\
$L_{s}$ & Separator thickness & 125 & $\mu \mathrm{m}$ & Measured \\
$C$ & Specific capacitance & 154.58 & $\mathrm{~F} / \mathrm{g}$ & Measured \\
$\mathrm{C}_{\mathrm{ini}}$ & Initial concentration & 1800 & $\mathrm{Mol} / \mathrm{m}^{3}$ & measured \\
$\mathrm{R}_{\mathrm{e}}$ & Electrode resistance & 19 & $\Omega / \mathrm{cm}^{2}$ & measured \\
$\mathrm{R}_{\mathrm{i}}$ & Electrolyte resistance & 29 & $\Omega / \mathrm{cm}^{2}$ & measured \\
$D_{i}$ & Diffusion coefficient of cation & $4.7 * 10^{-11}$ & $\mathrm{~m}^{2} / \mathrm{s}$ & Ref. [77] \\
$D_{i}$ & Diffusion coefficient of anion & $2.8 * 10^{-11}$ & $\mathrm{~m}^{2} / \mathrm{s}$ & Ref. [77] \\
$\alpha_{a}$ & Anodic rate transfer coefficients & 0.5 & - & Ref. [50] \\
$\alpha_{c}$ & Cathodic rate transfer & 0.5 & - & Ref. [50] \\
& coefficients & & & \\
$i_{0}$ & Exchange current density & 3.45 & $\mathrm{~mA} / \mathrm{cm}^{3}$ & measured \\
$\rho_{p}$ & Density of ionic liquid & 1.523 & $\mathrm{~g} / \mathrm{m}^{3}$ & Ref. [78] \\
$\mu$ & Dynamic viscosity of ionic liquid & 38.6 & $\mathrm{mPa} \cdot \mathrm{s}$ & Ref. [78] \\
$E$ & Young's Modulus of CPC & 278 & $\mathrm{MPa}$ & measured \\
$M_{s}$ & Molar mass of ionic liquid & 0.391 & $\mathrm{Kg} / \mathrm{mol}^{2}$ & Ref. [79] \\
$\beta_{s s}$ & Coefficient of swelling & $1.3 \mathrm{e}-5$ & $\mathrm{~m}{ }^{3} / \mathrm{kg}$ & Fitting parameter \\
$F$ & Faraday constant & 96485 & $\mathrm{KJ}$ & Constant \\
$R$ & Gas constant & 8.314 & $\mathrm{~J} \cdot \mathrm{mol}{ }^{-1} \cdot \mathrm{K}^{-1}$ & Constant \\
$T$ & Temperature & 293.15 & $\mathrm{~K}$ & Constant \\
\hline
\end{tabular}

\subsection{Displacement characteristics}

The manipulator comprising four individually controllable trilayer actuators was successfully fabricated using syringe-based printing method and saturated with ionic liquid. A 3D printed frame based on Polylactide thermoplastic was used as a supporting structure and was also used for connecting the electrical terminals. Figure 8 (a) shows the printed manipulator with the central platform and four actuators named 
top, bottom, left and right for convenience and figure 8 (b) shows the manipulator fixed to the printed frame with the electrical connection and a gold sputter-coated mirror fixed to the platform.

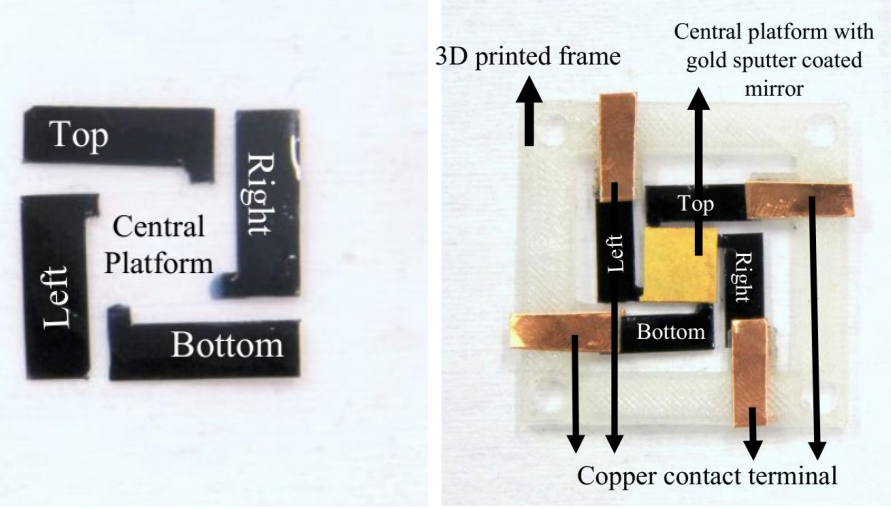

Fig. 8. (a) Printed manipulator with the central platform and four actuators (b) Manipulator fixed to the frame with electrical connection with a gold sputter-coated mirror fixed to the platform
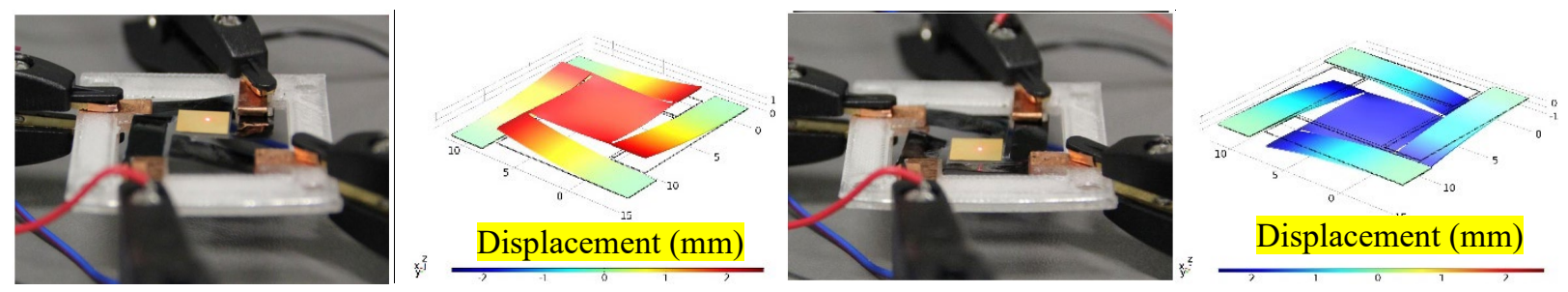

(a) Linear Motion
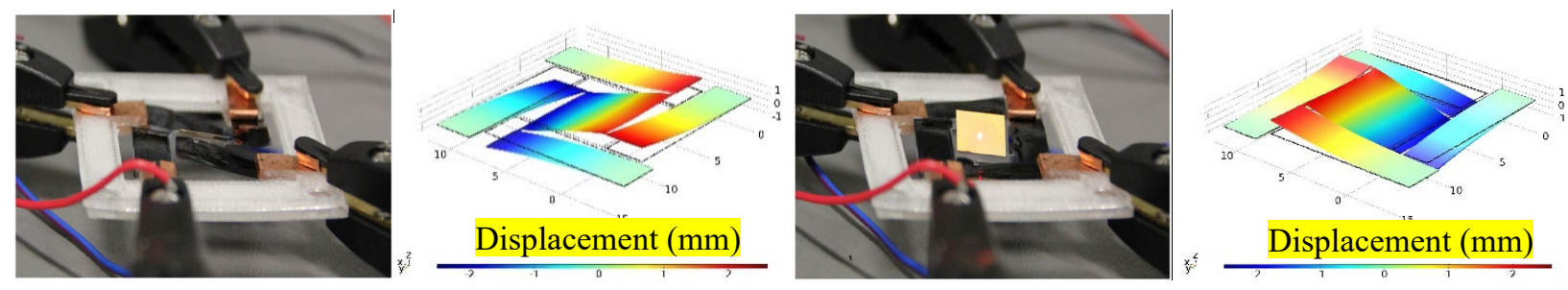

(b) Pitch Motion
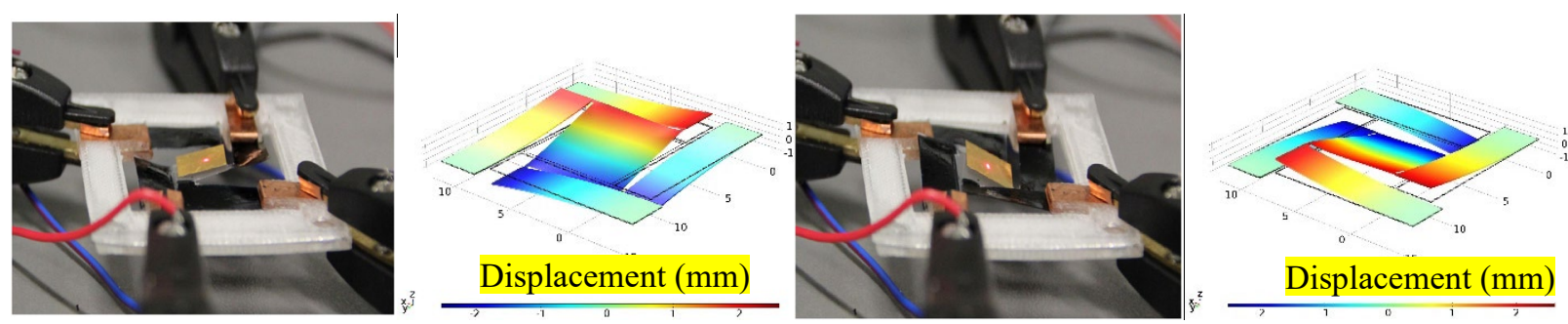

(c) Roll Motion

Fig. 9. Displacement and rotation movement of the fabricated manipulator and comparison with simulation results. (a) Linear motion showing maximum and minimum positions, (b) Pitch motion in both extreme rotational angles (c) Roll motion in both extreme rotational angles 
Next, the workspace of the manipulator was investigated. The photographs of the maximum linear movement and rotational motion along the different axis are shown in figure 9 and compared with the simulation model. The simulation results represent the surface plot of the actuator and the platform displacement with the legend representing the displacement gradient along the surface for piston, pitch and roll motion. The reddest and bluest colours represent the points of maximum and minimum displacements along the positive axis direction. The maximum tip to tip linear displacement achieved by the platform is $5.1 \mathrm{~mm}$ and the overall maximum rotation angle along the $\mathrm{X}$-axis is $11.36^{\circ}$ and along $\mathrm{Y}$-axis is $11.12^{\circ}$. The peak to peak linear stroke of about $5.1 \mathrm{~mm}$ generated with this system is higher compared to other designs presented earlier that are only capable of generating linear motion less than $1 \mathrm{~mm}$ [35-37,39] and is five times larger than the displacement achieved by the three spiral actuators made from polypyrrole actuators [34]. Also, in comparison to the maximum tilting angle of $11.3^{\circ}$ on one axis achieved earlier for mirror application [35] the printed device was able to generate similar angles in two different axes. In addition to achieving a larger displacement, this configuration is capable of generating three degrees of freedom motion all in a single compliant mechanism, unlike other systems where motion is reported only along one or two axes.

The comparison between the experimental and simulation values are shown in figure 10. The linear peak to peak piston motion from the simulation results predicts a displacement of $5.2 \mathrm{~mm}$ which is very close to the measured experimental value of $5.1 \mathrm{~mm}$ with a percentage error of $1.92 \%$ showing good agreement with the developed model. In the case of the rotational angles, the predicted values through simulation are $12.4^{\circ}$ on both the axis, whereas the experimental values are $11.12^{\circ}$ and $11.3^{\circ}$. The maximum error percentage is $10.3 \%$, the increase in error is assumed due to additional torsional forces acting on the joints between platform and actuators which are not included in the model during simulation. Nevertheless, the maximum error between experimental and simulation of about $10 \%$ is sufficient to characterize, visualise and optimize the system for further analysis and application development before fabrication. Also, this model can be integrated as a subcomponent into the model of other devices, such as an application (e.g. a camera zoom lens system), allowing to simulate the performance of the whole device before manufacturing. 


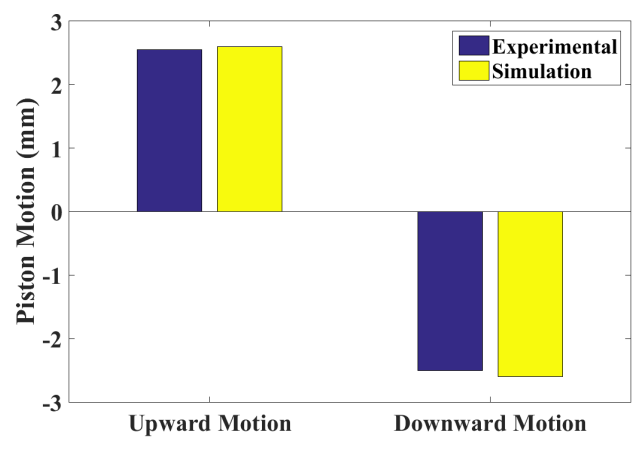

(a)

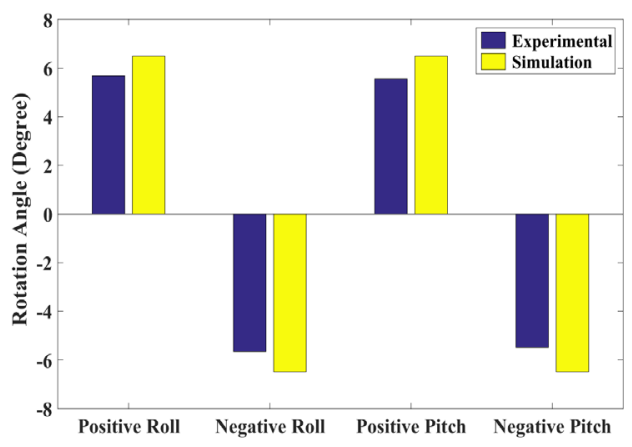

(b)

Fig. 10. Comparison of simulation and experimental results (a) Comparison between experimental and simulation for linear displacements (b) Comparison between experimental and simulation for rotational angles

\subsection{Dynamic displacement characterization}

To measure the rise time and the frequency response of the manipulator, square wave and sinusoidal potentials signals (the standard signals used to characterize the time domain and frequency domain behaviour of the system) were applied and the linear displacement of the platform was measured using a laser displacement sensor. With the square wave potential of $0.1 \mathrm{~Hz}$ and $+2 \mathrm{~V}$ to $-2 \mathrm{~V}$ the platform displaced from $-2.5 \mathrm{~mm}$ to $2.6 \mathrm{~mm}$ resulting in a total peak to peak displacement of $5.1 \mathrm{~mm}$. The rise time of the platform to reach $90 \%$ of its maximum displacement from the neutral position is $0.27 \mathrm{~s}$ and the response is shown in figure 11(a). For the frequency response measurement, the $2 \mathrm{~V}$ sinusoidal input signal is applied to the actuator with frequencies ranging from $0.1 \mathrm{~Hz}$ to $12 \mathrm{~Hz}$ (figure 11(b)). The peak to peak displacement is about $5.1 \mathrm{~mm}$ at $0.1 \mathrm{~Hz}$ and progressively decreases as the frequency increases to become negligible at frequencies higher than $12 \mathrm{~Hz}$ as these devices are rate limited due to slow ion transport process [9]. There was no creep found in the actuators during the first 50 cycles, and also there were no delamination effects. However, beyond an average of 50 cycles of continuous operation at $\pm 2 \mathrm{~V}$, the actuation or displacement reduces considerably. The decrease in the displacement may be due to various factors [80] such as (1) decomposition of the electrolyte under electrochemical cycling (2) delamination of the electrodes from the membrane due to stresses at the interface and (3) non-reversible redox processes in the CP layers occurring at high potentials which deteriorate the $\mathrm{CP}$ material. A further detailed study needs to be conducted to comprehend the exact cause for decreased displacement occurring in our actuator configuration. Nevertheless, the developed manipulator with PEDOT:PSS electrodes provided a very quick response speed of $0.27 \mathrm{~s}$ as compared to a similar platform made out of carbon composite [40], which had a rise time of $18 \mathrm{~s}$. Also the rotational angle of $1.02 \% \mathrm{~mm}$ length of the PEDOT:PSS actuator was higher than that of the previous carbon composite based system which was $0.76^{\%} / \mathrm{mm}\left(+/-15^{0}\right.$ for a $40 \mathrm{~mm}$ long actuator) The 
linear displacement of this printed PEDOT:PSS system, however, was slightly less than that system $5.1 \mathrm{~mm}$ or $0.46 \mathrm{~mm}$ per mm length versus $\pm 15 \mathrm{~mm}$ or $0.75 \mathrm{~mm}$ per mm length generated by carbon composite (40 $\mathrm{mm}$ long and $10 \mathrm{~mm}$ wide).

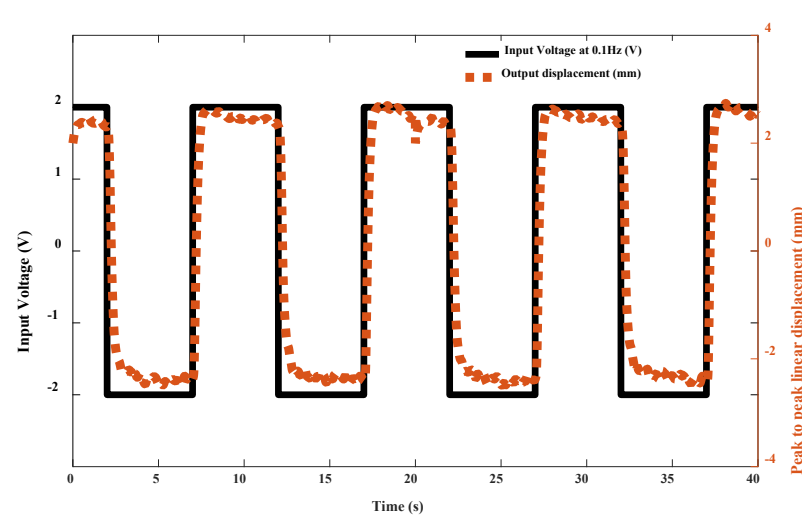

(a)

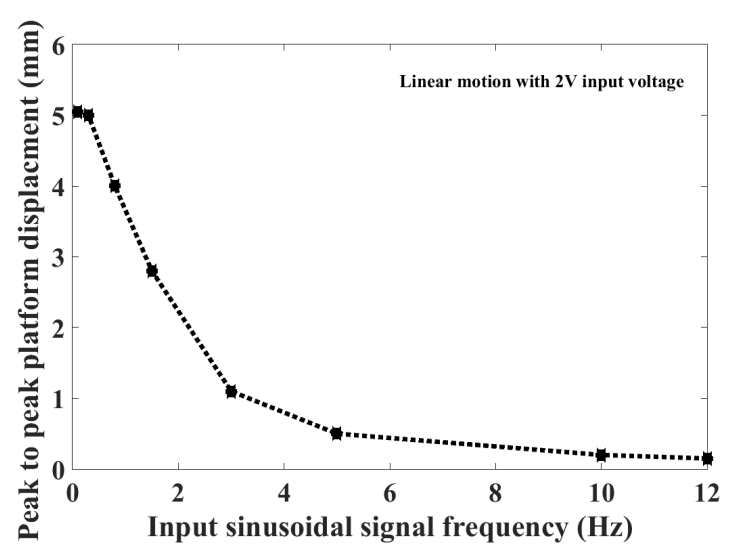

(b)

Fig. 11. (a) Input voltage of $2 \mathrm{~V}$ square wave signal and output linear displacement of the actuator at 0.1 $\mathrm{Hz}$ (b) Frequency Response of peak to peak displacement from $0.1 \mathrm{~Hz}$ to $12 \mathrm{~Hz}$

Other advantages of this printed PEDOT:PSS based system is that it is nearly three times smaller in terms of overall surface area $\left(16 \times 16 \mathrm{~mm}^{2}\right.$ vs $\left.53 \times 53 \mathrm{~mm}^{2}\right)$ making it very compact while at the same time being able to be batch fabricated only using commercially available off the shelf materials, which was not the case for the handmade carbon composite based system.

\subsection{Blocking force measurements}

Next, experiments were conducted to measure the blocking force generated by the manipulator and the measurement results are shown in figure 12. The experimental arrangement of the force measurement setup positioned at the center of the platform is shown in figure 12(a). For the applied $2 \mathrm{~V}$ step voltage signal, the maximum blocking force generated by the manipulator is $0.6 \mathrm{mN}$ and the rise time for reaching $90 \%$ of the force is $0.7 \mathrm{~s}$ and is shown in figure 12(b). The frequency response of the generated force for a sinusoidal input signal of frequency ranging from $0.1 \mathrm{~Hz}$ to $8 \mathrm{~Hz}$ is shown in figure 12(c). As the frequency increases, the force reduces from $0.6 \mathrm{mN}$ to $0.015 \mathrm{mN}$ at $8 \mathrm{~Hz}$. The force response is slower compared to the displacement response which is accounted for that the stress is distributed along the length of the actuator and is maximum near the fixed contacts. Since, the platform is blocked to move from its position by the force transducers the force starts to generate near the fixed contacts initially and travels along the actuator and to the platform taking significant amount of time, whereas during displacement measurement the actuators are free to move along the length of the actuators and the platform is synchronized to the actuator 
movement. A small back relaxation (small decrease of the force) is seen after 2.5 seconds on the blocking force.

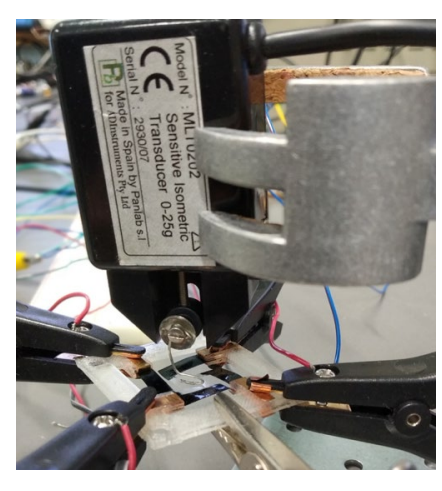

(a)

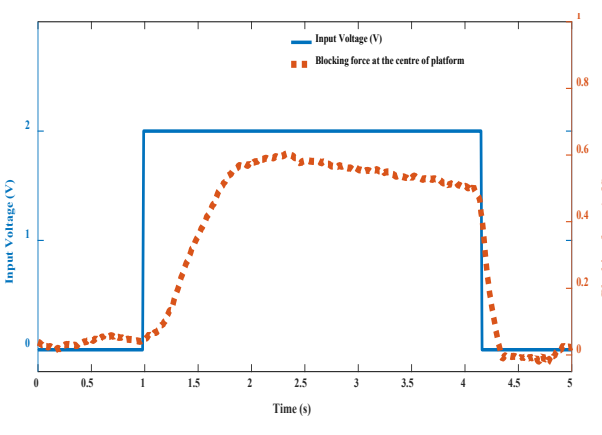

(b)

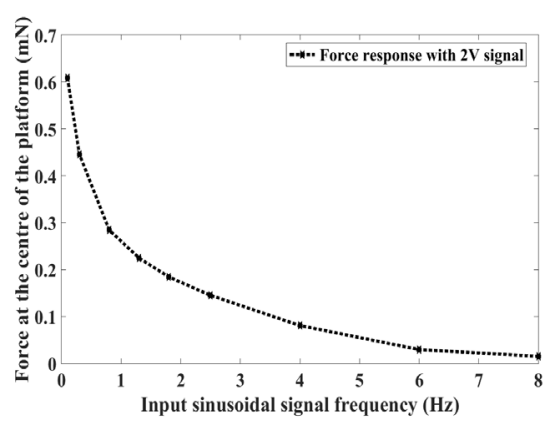

(c)

Fig. 12. (a) Photograph of the force measurement setup (b) Force response for step input voltage with maximum force of $0.6 \mathrm{mN}$ (c) Frequency response of developed force for the frequency range from 0.1 $\mathrm{Hz}$ to $8 \mathrm{~Hz}$

\subsection{Laser steering application}

In order to demonstrate a possible application of the developed manipulator, a laser steering application was designed and used as an optical switch. The experimental arrangement consisted of four light dependent resistors (LDR) fixed at a predetermined position (at the boundary of the workspace) as shown in figure 13(a) and the electrical circuit of the LDR is shown in figure 13(b). On the incident of light onto the surface of the resistor, the resistance changes causing a change in potential which can be measured. This change in potential can be used as a switching action to trigger further actions or processes. The manipulator is fixed at a defined position and a laser beam is directed onto the mirror of the manipulator. The actuators are activated in an automated sequence such that the mirror steers the light from the laser on the surface of the LDR, triggering the switch action. By manipulating each of the actuators, the LDR's can be switched ON/OFF optically in the desired sequence. It is possible to have a series of LDR's within the workspace of the manipulator and trigger each resistor precisely by controlling the manipulator achieving a multiplexed optical switch, but for the purpose of this demonstration, only four LDR's are used. The input switching signals to the manipulator actuators are shown in figure 14. The LDR switching responses and the photographs of each switching action are shown in 15(a) and 15(b). The manipulator was able to achieve fast switching action with 0.84 s to trigger from the complete OFF state to ON state. Apart from switching, this ability of the manipulator to steer light in the $\mathrm{X}-\mathrm{Y}$ axis have other potential laser steering optical application. Also, manipulator systems like this with a high rotation angle $\left(>10^{\circ}\right)$ are considered to be 
sufficient for use in the display modules [35]. The optical switching demonstrated here is a proof of concept for showing the manipulator's ability to move in X-Y axis, but it cannot be a viable replacement for the commercial optical switch since the frequency of operation of such switches are typically in $\mathrm{kHz}$ frequency. Nevertheless, this demonstration clearly shows the manipulation capabilities of this compact, thin manipulator operating a in a compact space.

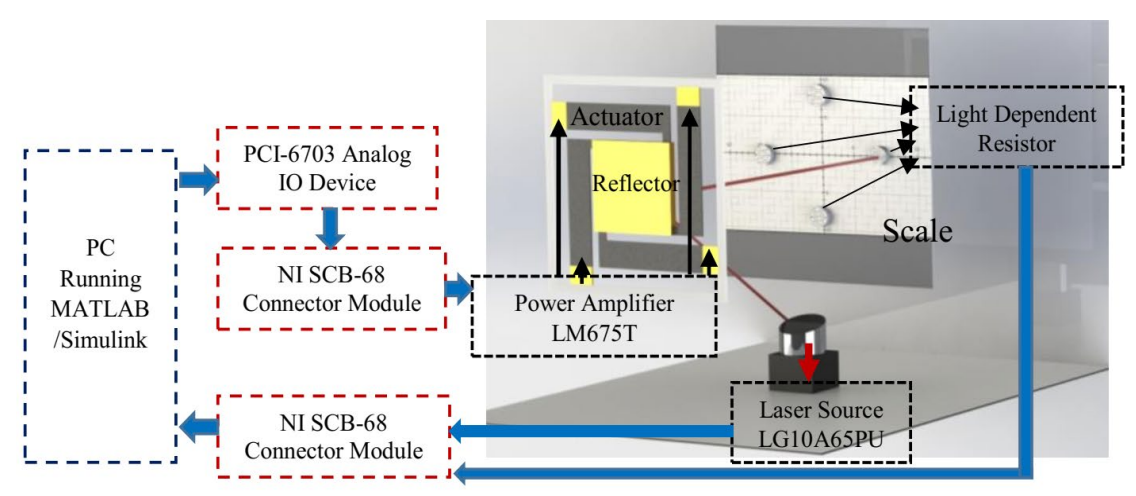

(a)

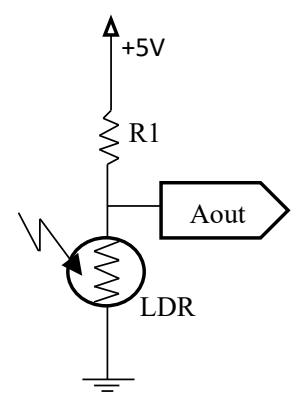

(b)

Fig. 13. (a) Schematics of the optical switch application with input/output connection to the manipulator and LDR position at a predetermined position (b) LDR Sensor electrical connection for potential measurement 


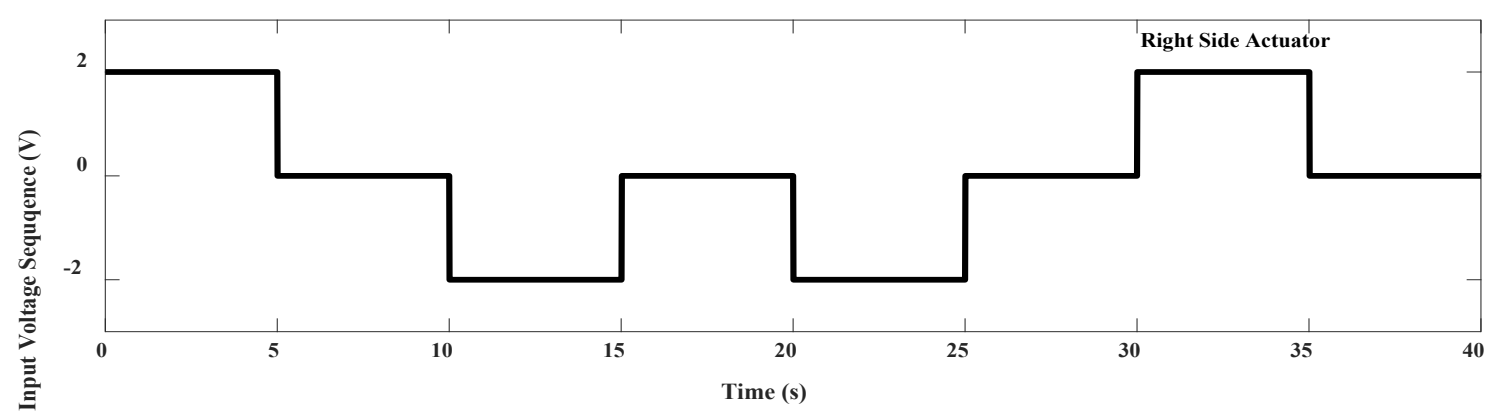

(a)

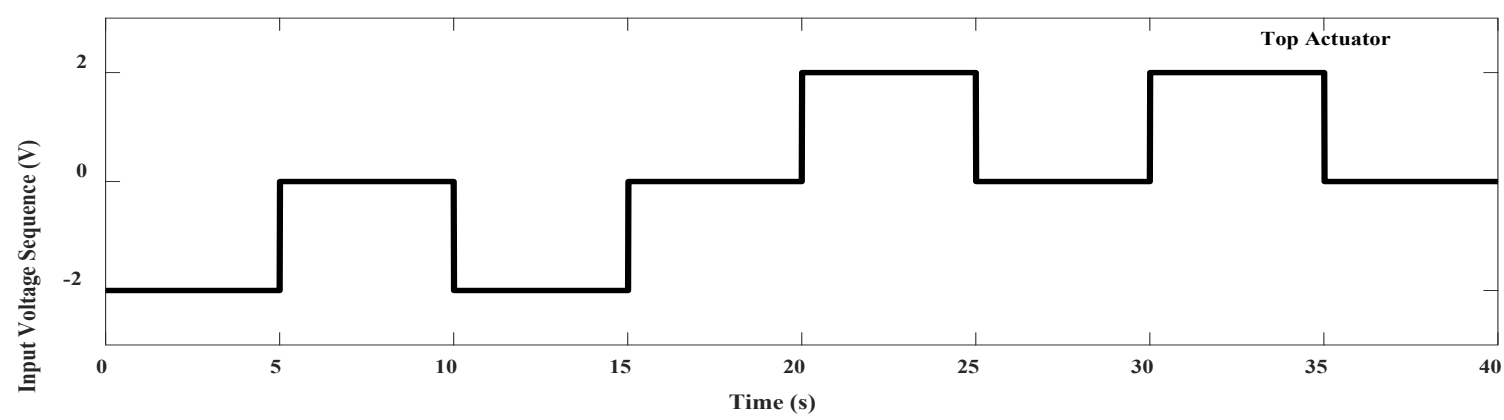

(b)

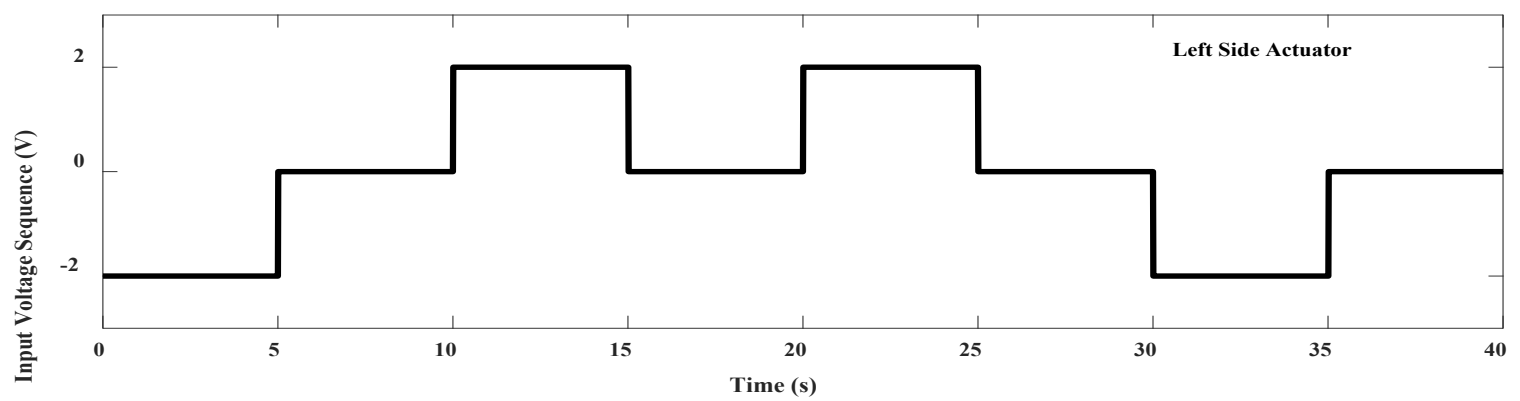

(c)

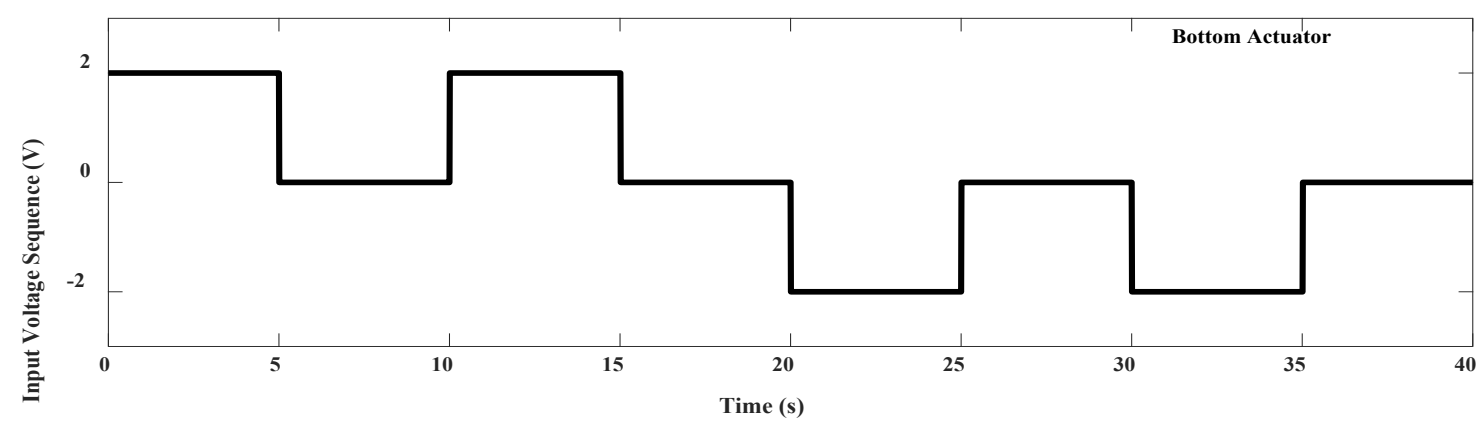

(d)

Fig. 14. (a-d) Automated trigger signal sequence to the each of the actuators (denoted as top, right, bottom and left) of the manipulator. 


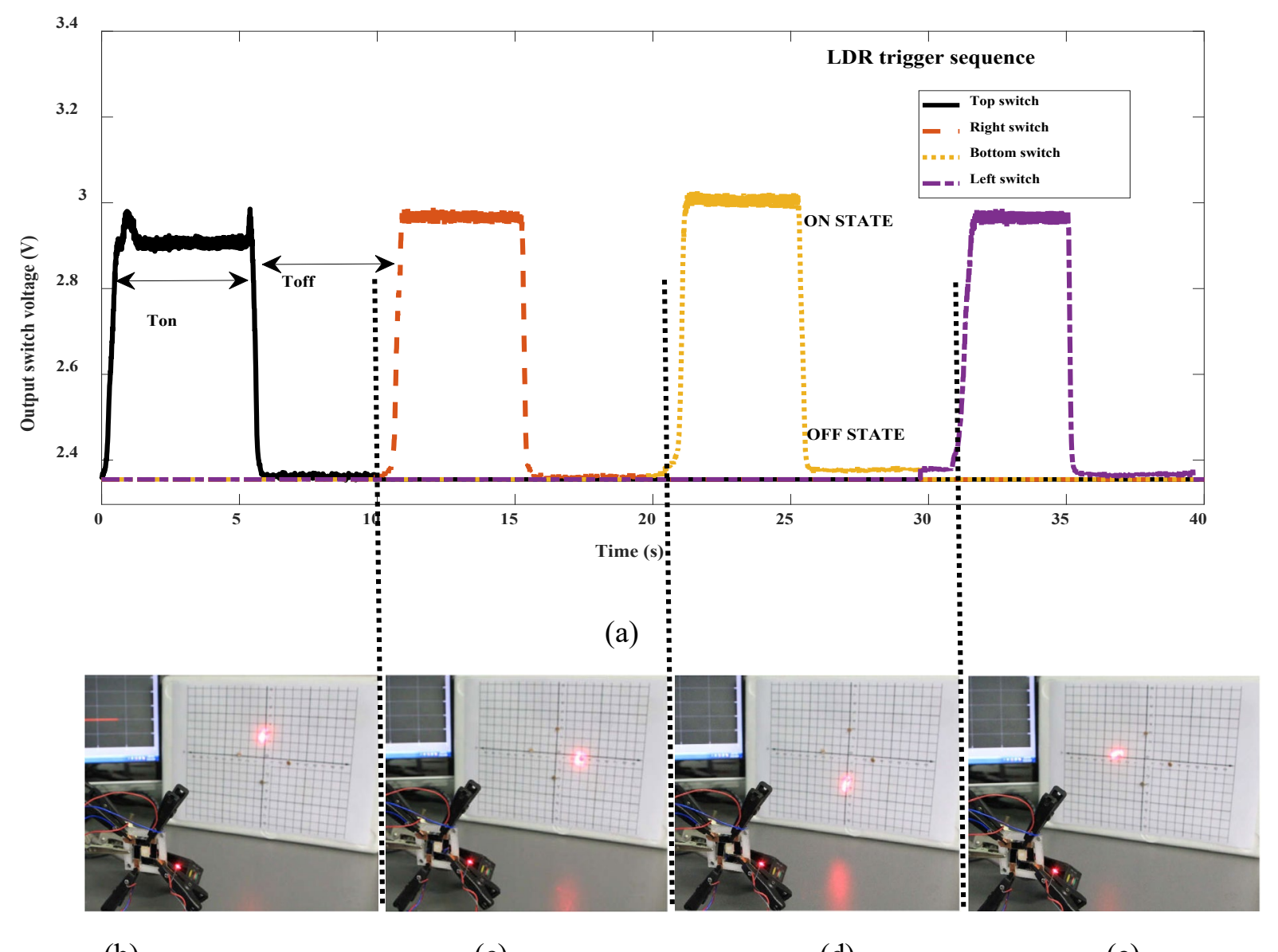

(b)

(c)

(d)

(e)

Fig. 15. Optical switching of four LDR sensor in the X-Y plane at the boundary of the workspace of the manipulator (a) The response of the four LDR switching from OFF state to ON state in accordance to the actuator switching sequence. (b-e) Photographs showing the laser spot at the four positions switching the LDR

\section{Conclusion}

In this work, the printing of a novel parallel manipulation system using commercially available off the shelf materials which is simpler, scalable and cost-effective is presented, including modelling and characterization thereof. Using the 3D syringe-based printer, we could print PEDOT:PSS lines down to 100 um line widths and 15 um thick layers during a single pass. The developed system was manipulated by four independently controllable conducting polymer actuators and was capable of moving in 3 degrees of freedom, i.e. rotating around two axes (pitch and roll) and linear displacement along one axis. The complete system was fabricated as a monolithic structure and FEM analysis was used to model the charge storage kinetics of the proposed mechanism and is compared with the experimental results. The model based on electro chemo mechanical dynamics was presented including charge contributions by both double layer 
charging/discharging as well as redox process. Through simulations, the charge contributed by each process was separated which presented new insights on the underlying kinetics in this type of actuators. It is found that the double layer charge contributes the most charge and is the dominant phenomenon driving these printed PEDOT actuators. The experimental results showed rotation angles of 11.36 degrees on two axes and $5.1 \mathrm{~mm}$ linear displacement along one axis with $0.27 \mathrm{~s}$ rise time. In considering the larger linear and angular motion with three degrees of motion and high speed of response, the printed manipulator outperformed previous devices in terms of smart material behaviour and has great potential for soft robotic applications. As an application example demonstrating its manipulation capabilities, a four-way optical switch using the manipulator was demonstrated showing the capability of optically triggering four switches in the $\mathrm{X}-\mathrm{Y}$ plane in an automated sequence. This clearly illustrates the ability of the monolithic flat printed actuators to manipulate in the $\mathrm{X}-\mathrm{Y}$ plane, which is a much simpler system as compared to two servo motors that are normally required for such applications. The application of the developed system can be extended to other potential applications such as a zoom lens, a microscope stage, laser steering, autofocusing systems, and micromirror. The developed manipulator would reduce the size and complexity of such systems, while at the same time it is fabricated using low cost commercially available 3D printers using off the shelf materials. The use of 3D printing eliminates the complex chemical synthesis method used for fabricating ionic actuators and also opens the opportunity to print a matrix array of identical actuators over a wide size scale. The whole system can also potentially be further reduced in size by using customized printing and microfabrication technologies $[3,13,81]$. The future direction of the work is to integrate a strain sensor as a part of the monolithic structure with the onboard closed-loop controller to control each of the actuators to make an autonomous motion system.

Acknowledgement: The research was supported by European Union's Horizon 2020 research and innovation program under the Marie Sklodowska Curie grant agreement No. 641822, the Institutional Research Funding project IUT20-24 from the Estonian Research Council, Linköping University, Swedish Research Council (VR-2014-3079), Promobilia Stiftelsen (F17603). The authors express their gratitude to Prof.-Nathaniel D Robinson and Prof. Daniel Filippini for providing guidance to use the instruments used in the research.

\section{References:}

[1] Y. Bahramzadeh, M. Shahinpoor, A Review of Ionic Polymeric Soft Actuators and Sensors, Soft Robot. 1 (2014) 38-52. doi:10.1089/soro.2013.0006.

[2] E. Smela, O. Inganas, I. Lundstrom, Conducting polymers as artificial muscles: Challenges and possibilities, J. Micromechanics Microengineering. 3 (1993) 203-205. doi:10.1088/0960- 
$1317 / 3 / 4 / 008$.

[3] E.W. Jager, E. Smela, O. Inganäs, Microfabricating conjugated polymer actuators., Science. 290 (2000) 1540-5. doi:10.1126/SCIENCE.290.5496.1540.

[4] T.F. Otero, Reactive conducting polymers as actuating sensors and tactile muscles, Bioinspiration and Biomimetics. 3 (2008) 035004. doi:10.1088/1748-3182/3/3/035004.

[5] E.W.H. Jager, N. Masurkar, N.F. Nworah, B. Gaihre, G. Alici, G.M. Spinks, Patterning and electrical interfacing of individually controllable conducting polymer microactuators, Sensors Actuators, B Chem. 183 (2013) 283-289. doi:10.1016/j.snb.2013.02.075.

[6] I. Põldsalu, S.-E. Mändmaa, A.-L. Peikolainen, A. Kesküla, A. Aabloo, Fabrication of ionconducting carbon-polymer composite electrodes by spin-coating, in: Y. Bar-Cohen (Ed.), Electroact. Polym. Actuators Devices 2015, 2015: p. 943019. doi:10.1117/12.2084180.

[7] A. Simaite, C. Bergaud, B. Tondu, P. Souéres, F. Mathieu, Simple casting based fabrication of PEDOT:PSS-PVDF-ionic liquid soft actuators, in: Y. Bar-Cohen (Ed.), Electroact. Polym. Actuators Devices 2015, International Society for Optics and Photonics, 2015: p. 94301E. doi:10.1117/12.2083936.

[8] J.J. Saarinen, M. Toivakka, J. Liu, V. Kumar, C. Xu, D. Valtakari, Conductivity of PEDOT:PSS on Spin-Coated and Drop Cast Nanofibrillar Cellulose Thin Films, Nanoscale Res. Lett. 10 (2015) 386. doi:10.1186/s11671-015-1093-y.

[9] A. Maziz, C. Plesse, C. Soyer, C. Chevrot, D. Teyssié, E. Cattan, F. Vidal, Demonstrating kHz frequency actuation for conducting polymer microactuators, Adv. Funct. Mater. 24 (2014) 48514859. doi:10.1002/adfm.201400373.

[10] R. Kiefer, T. Tamm, M.S. Khorram, I. Põldsalu, A.-L. Peikolainen, K. Rohtlaid, C. Plesse, T.M.G. Nguyen, F. Vidal, Thin ink-jet printed trilayer actuators composed of PEDOT:PSS on interpenetrating polymer networks, Sensors Actuators B Chem. 258 (2017) 1072-1079. doi:10.1016/j.snb.2017.11.147.

[11] I. Põldsalu, M. Harjo, T. Tamm, M. Uibu, A.L. Peikolainen, R. Kiefer, Inkjet-printed hybrid conducting polymer-activated carbon aerogel linear actuators driven in an organic electrolyte, Sensors Actuators, B Chem. 250 (2017) 44-51. doi:10.1016/j.snb.2017.04.138.

[12] C. Bergaud, B. Tondu, P. Souères, F. Mesnilgrente, A. Simaite, Towards inkjet printable conducting polymer artificial muscles, Sensors Actuators B Chem. 229 (2016) 425-433. 
doi:10.1016/j.snb.2016.01.142.

[13] A. Khaldi, D. Falk, K. Bengtsson, A. Maziz, D. Filippini, N.D. Robinson, E.W.H. Jager, Patterning Highly Conducting Conjugated Polymer Electrodes for Soft and Flexible Microelectrochemical Devices, ACS Appl. Mater. Interfaces. 10 (2018) 14978-14985. doi:10.1021/acsami.8b01059.

[14] P.J. Sebastian, M.E. Calixto, Porous CdS:CdO composite structure formed by screen printing and sintering of CdS in air, Thin Solid Films. 360 (2000) 128-132. doi:10.1016/S0040-6090(99)010883.

[15] D.K. Patel, A.H. Sakhaei, M. Layani, B. Zhang, Q. Ge, S. Magdassi, Highly Stretchable and UV Curable Elastomers for Digital Light Processing Based 3D Printing, Adv. Mater. 29 (2017). doi:10.1002/adma.201606000.

[16] M.K. Hod Lipson, Fabricated The New World of 3D Printing, John Wiley\&Sons ,Inc, 1st Ed. (2013) 1-5. doi:10.1007/s13398-014-0173-7.2.

[17] I. Gibson, D. Rosen, B. Stucker, Additive manufacturing technologies: 3D printing, rapid prototyping, and direct digital manufacturing, second edition, Springer US, 2015. doi:10.1007/9781-4939-2113-3.

[18] K. Bengtsson, Additive manufacturing methods and materials for electrokinetic systems, Linköping University, 2015. doi:10.3384/lic.diva-121252.

[19] A.T. Cullen, A.D. Price, Digital light processing for the fabrication of 3D intrinsically conductive polymer structures, Synth. Met. 235 (2018) 34-41. doi:10.1016/j.synthmet.2017.11.003.

[20] D. Wang, C. Lu, J. Zhao, S. Han, M. Wu, W. Chen, High energy conversion efficiency conducting polymer actuators based on PEDOT:PSS/MWCNTs composite electrode, RSC Adv. 7 (2017) 31264-31271. doi:10.1039/c7ra05469f.

[21] U.L. Zainudeen, M.A. Careem, S. Skaarup, PEDOT and PPy conducting polymer bilayer and trilayer actuators, Sensors Actuators, B Chem. 134 (2008) 467-470. doi:10.1016/j.snb.2008.05.027.

[22] S.H. Eom, S. Senthilarasu, P. Uthirakumar, S.C. Yoon, J. Lim, C. Lee, H.S. Lim, J. Lee, S.H. Lee, Polymer solar cells based on inkjet-printed PEDOT:PSS layer, Org. Electron. Physics, Mater. Appl. 10 (2009) 536-542. doi:10.1016/j.orgel.2009.01.015.

[23] B.J. De Gans, P.C. Duineveld, U.S. Schubert, Inkjet printing of polymers: State of the art and future developments, Adv. Mater. 16 (2004) 203-213. doi:10.1002/adma.200300385. 
[24] T. Hirai, Dielectric gels, in: Soft Actuators Mater. Model. Appl. Futur. Perspect., Springer Japan, Tokyo, 2014: pp. 169-182. doi:10.1007/978-4-431-54767-9_12.

[25] B. Derby, Inkjet Printing of Functional and Structural Materials: Fluid Property Requirements, Feature Stability, and Resolution, Annu. Rev. Mater. Res. 40 (2010) 395-414. doi:10.1146/annurevmatsci-070909-104502.

[26] I. Põldsalu, K. Rohtlaid, T.M.G. Nguyen, C. Plesse, F. Vidal, M.S. Khorram, A.L. Peikolainen, T. Tamm, R. Kiefer, Thin ink-jet printed trilayer actuators composed of PEDOT:PSS on interpenetrating polymer networks, Sensors Actuators, B Chem. 258 (2018) 1072-1079. doi:10.1016/j.snb.2017.11.147.

[27] D. Pranzo, P. Larizza, D. Filippini, G. Percoco, Extrusion-Based 3D Printing of Microfluidic Devices for Chemical and Biomedical Applications: A Topical Review, Micromachines. 9 (2018) 374. doi:10.3390/mi9080374.

[28] M.S. Mannoor, Z. Jiang, T. James, Y.L. Kong, K.A. Malatesta, W.O. Soboyejo, N. Verma, D.H. Gracias, M.C. McAlpine, 3D printed bionic ears, Nano Lett. 13 (2013) 2634-2639. doi:10.1021/n14007744.

[29] H.N. Chia, B.M. Wu, Recent advances in 3D printing of biomaterials., J. Biol. Eng. 9 (2015) 4. doi:10.1186/s13036-015-0001-4.

[30] J.-S. Lee, J.M. Hong, J.W. Jung, J.-H. Shim, J.-H. Oh, D.-W. Cho, 3D printing of composite tissue with complex shape applied to ear regeneration., Biofabrication. 6 (2014) 024103. doi:10.1088/1758-5082/6/2/024103.

[31] L.A. Hockaday, K.H. Kang, N.W. Colangelo, P.Y.C. Cheung, B. Duan, E. Malone, J. Wu, L.N. Girardi, L.J. Bonassar, H. Lipson, C.C. Chu, J.T. Butcher, Rapid 3D printing of anatomically accurate and mechanically heterogeneous aortic valve hydrogel scaffolds., Biofabrication. 4 (2012) 035005. doi:10.1088/1758-5082/4/3/035005.

[32] G. Alici, R. Mutlu, D. Melling, E.W.H. Jager, K. Kaneto, Conducting Polymers as EAPs: Device Configurations, in: Electromechanically Act. Polym., Springer International Publishing, 2016: pp. 1-35. doi:10.1007/978-3-319-31767-0_12-1.

[33] I. Must, V. Vunder, F. Kaasik, I. Põldsalu, U. Johanson, A. Punning, A. Aabloo, Ionic liquid-based actuators working in air: The effect of ambient humidity, Sensors Actuators, B Chem. 202 (2014) 114-122. doi:10.1016/j.snb.2014.05.074. 
[34] R. Mutlu, G. Alici, W. Li, A Soft Mechatronic Microstage Mechanism Based on Electroactive Polymer Actuators, IEEE/ASME Trans. Mechatronics. 21 (2016) 1467-1478. doi:10.1109/TMECH.2015.2502597.

[35] H.U. Yun, C.J. Kim, S.J. Kim, N.C. Park, H. Yang, Y.-P. Park, Design of micromirror actuator by ionic polymer metal composites, Microsyst. Technol. 15 (2009) 1531-1538. doi:10.1007/s00542009-0801-x.

[36] S.-A. Tsai, H.-C. Wei, G.-D.J. Su, Polydimethylsiloxane coating on an ionic polymer metallic composite for a tunable focusing mirror, Appl. Opt. 51 (2012) 8315. doi:10.1364/ao.51.008315.

[37] W.-H. Chen, J.-S. Lu, G.-D.J. Su, Ionic polymer metal composite for an optical zoom in a compact camera, Opt. Express. 23 (2015) 13265. doi:10.1364/oe.23.013265.

[38] M. Yamakita, N. Kamamichi, Y. Kaneda, K. Asaka, Z.-W. Luo, Development of an artificial muscle linear actuator using ionic polymer-metal composites, Adv. Robot. 18 (2004) 383-399. doi:10.1163/156855304773822473.

[39] J. Torop, M. Arulepp, J. Leis, A. Punning, U. Johanson, V. Palmre, A. Aabloo, Nanoporous carbidederived carbon material-based linear actuators, Materials (Basel). 3 (2010) 9-25. doi:10.3390/ma3010009.

[40] A. Aabloo, S. Nakshatharan, A. Punning, U. Johanson, Fabrication of carbon polymer composite manipulated multi-degree motion platform, in: Y. Bar-Cohen (Ed.), Electroact. Polym. Actuators Devices XX, SPIE, 2018: p. 68. doi:10.1117/12.2300752.

[41] N. Terasawa, K. Asaka, High-Performance PEDOT:PSS/Single-Walled Carbon Nanotube/Ionic Liquid Actuators Combining Electrostatic Double-Layer and Faradaic Capacitors, Langmuir. 32 (2016) 7210-7218. doi:10.1021/acs.langmuir.6b01148.

[42] N. Terasawa, K. Asaka, High-Performance Hybrid (Electrostatic Double-Layer and Faradaic Capacitor-Based) Polymer Actuators Incorporating Nickel Oxide and Vapor-Grown Carbon Nanofibers, Langmuir. 30 (2014) 14343-14351. doi:10.1021/la503468z.

[43] S.-S. Kim, J.-H. Jeon, C.-D. Kee, I.-K. Oh, Electro-active hybrid actuators based on freeze-dried bacterial cellulose and PEDOT:PSS, Smart Mater. Struct. 22 (2013) 085026. doi:10.1088/0964$1726 / 22 / 8 / 085026$.

[44] https://www.creativemachineslab.com/fabhome.html. 
[45] T. Tevi, S.W. Saint Birch, S.W. Thomas, A. Takshi, Effect of Triton X-100 on the double layer capacitance and conductivity of poly(3,4-ethylenedioxythiophene):poly(styrenesulfonate) (PEDOT:PSS) films, Synth. Met. 191 (2014) 59-65. doi:10.1016/j.synthmet.2014.02.005.

[46] Q. Pei, O. Inganäs, Electrochemical applications of the bending beam method. 1. Mass transport and volume changes in polypyrrole during redox, J. Phys. Chem. 96 (1992) 10507-10514. doi:10.1021/j100204a071.

[47] A. Punning, V. Vunder, I. Must, U. Johanson, G. Anbarjafari, A. Aabloo, In situ scanning electron microscopy study of strains of ionic electroactive polymer actuators, J. Intell. Mater. Syst. Struct. 27 (2016) 1061-1074. doi:10.1177/1045389X15581520.

[48] T. Shoa, D.S. Yoo, K. Walus, J.D.W. Madden, A dynamic electromechanical model for electrochemically driven conducting polymer actuators, IEEE/ASME Trans. Mechatronics. 16 (2011) 42-49. doi:10.1109/TMECH.2010.2090166.

[49] Y. Liu, R. Zhao, M. Ghaffari, J. Lin, S. Liu, H. Cebeci, R.G. De Villoria, R. Montazami, D. Wang, B.L. Wardle, J.R. Heflin, Q.M. Zhang, Equivalent circuit modeling of ionomer and ionic polymer conductive network composite actuators containing ionic liquids, Sensors Actuators, A Phys. 181 (2012) 70-76. doi:10.1016/j.sna.2012.05.002.

[50] T.F. Otero, J.G. Martinez, Structural and biomimetic chemical kinetics: Kinetic magnitudes include structural information, Adv. Funct. Mater. 23 (2013) 404-416. doi:10.1002/adfm.201200719.

[51] T.F. Otero, J.G. Martinez, Physical and chemical awareness from sensing polymeric artificial muscles. Experiments and modeling, Prog. Polym. Sci. 44 (2015) 62-78. doi:10.1016/J.PROGPOLYMSCI.2014.09.002.

[52] G. Alici, P. Metz, G.M. Spinks, A methodology towards geometry optimization of high performance polypyrrole (PPy) actuators, Smart Mater. Struct. 15 (2006) 243-252. doi:10.1088/0964$1726 / 15 / 2 / 003$.

[53] P. Metz, G. Alici, G.M. Spinks, A finite element model for bending behaviour of conducting polymer electromechanical actuators, Sensors Actuators, A Phys. 130-131 (2006) 1-11. doi:10.1016/j.sna.2005.12.010.

[54] T. Wallmersperger, D.J. Leo, C.S. Kothera, Transport modeling in ionomeric polymer transducers and its relationship to electromechanical coupling, J. Appl. Phys. 101 (2007) 024912. doi:10.1063/1.2409362. 
[55] T. Stalbaum, D. Pugal, S.E. Nelson, V. Palmre, K.J. Kim, Physics-based modeling of mechanoelectric transduction of tube-shaped ionic polymer-metal composite, J. Appl. Phys. 117 (2015) 114903. doi:10.1063/1.4914034.

[56] Q. Shen, V. Palmre, T. Stalbaum, K.J. Kim, A comprehensive physics-based model encompassing variable surface resistance and underlying physics of ionic polymer-metal composite actuators, J. Appl. Phys. 118 (2015) 124904. doi:10.1063/1.4931912.

[57] C.H. Jenkins, S.K. Khanna, Mechanics of materials: a modern integration of mechanics and materials in structural design, Elsevier Academic Press, 2005.

[58] T. Brousse, D. Bélanger, J.W. Long, To Be or Not To Be Pseudocapacitive?, J. Electrochem. Soc. 162 (2015) A5185-A5189. doi:10.1149/2.0201505jes.

[59] E.W.H. Jager, Conducting polymer actuators for medical devices and cell mechanotransduction, in: 2013 IEEE/ASME Int. Conf. Adv. Intell. Mechatronics, IEEE, 2013: pp. 1661-1666. doi:10.1109/AIM.2013.6584335.

[60] B.E. Conway, Electrochemical Supercapacitors, Springer US, Boston, MA, 1999. doi:10.1007/9781-4757-3058-6.

[61] S. Ghosh, O. Inganäs, Conducting Polymer Hydrogels as 3D Electrodes: Applications for Supercapacitors, Adv. Mater. $11 \quad$ (2002) 1214-1218. doi:10.1002/(sici)15214095(199910)11:14<1214::aid-adma1214>3.0.co;2-3.

[62] T.F. Otero, J.M. Sansiñena, Soft and wet conducting polymers for artificial muscles, Adv. Mater. 10 (1998) 491-494. doi:10.1002/(SICI)1521-4095(199804)10:6<491::AID-ADMA491>3.0.CO;2Q.

[63] J.G. Martinez, T.F. Otero, Biomimetic Dual Sensing-Actuators: Theoretical Description. Sensing Electrolyte Concentration and Driving Current, J. Phys. Chem. B. 116 (2012) 9223-9230. doi:10.1021/jp302931k.

[64] L. Bay, T. Jacobsen, S. Skaarup, K. West, Mechanism of actuation in conducting polymers: Osmotic expansion, J. Phys. Chem. B. 105 (2001) 8492-8497. doi:10.1021/jp003872w.

[65] P. Giménez, K. Mukai, K. Asaka, K. Hata, H. Oike, T.F. Otero, Capacitive and faradic charge components in high-speed carbon nanotube actuator, Electrochim. Acta. 60 (2012) 177-183. doi:10.1016/J.ELECTACTA.2011.11.032. 
[66] K.J. Vetter, Electrochemical kinetics: theoretical and experimental aspects, New York, N.Y: Academic Press, 1967.

[67] M.W. Verbrugge, P. Liu, Microstructural Analysis and Mathematical Modeling of Electric DoubleLayer Supercapacitors, J. Electrochem. Soc. 152 (2005) D79. doi:10.1149/1.1878052.

[68] A. V. Volkov, K. Wijeratne, E. Mitraka, U. Ail, D. Zhao, K. Tybrandt, J.W. Andreasen, M. Berggren, X. Crispin, I. V. Zozoulenko, Understanding the Capacitance of PEDOT:PSS, Adv. Funct. Mater. 27 (2017) 1700329. doi:10.1002/adfm.201700329.

[69] S. Sunjai Nakshatharan, A. Punning, U. Johanson, A. Aabloo, Effect of porosity and tortuosity of electrodes on carbon polymer soft actuators, J. Appl. Phys. 123 (2018) 014502. doi:10.1063/1.5007147.

[70] B.A. Mei, O. Munteshari, J. Lau, B. Dunn, L. Pilon, Physical Interpretations of Nyquist Plots for EDLC Electrodes and Devices, J. Phys. Chem. C. 122 (2018) 194-206. doi:10.1021/acs.jpcc.7b10582.

[71] R. Drummond, D.A. Howey, S.R. Duncan, Low-order mathematical modelling of electric double layer supercapacitors using spectral methods, J. Power Sources. 277 (2015) 317-328. doi:10.1016/j.jpowsour.2014.11.116.

[72] J. Newman, K.E. Thomas-Alyea, Electrochemical Systems, J. Wiley, 2004. https://www.wiley.com/en-us/Electrochemical+Systems\%2C+3rd+Edition-p-9780471477563 (accessed March 29, 2019).

[73] K.E. Heusler, L. Gaiser, The Mechanism of the Cadmium Electrode, J. Electrochem. Soc. 117 (2007) 762. doi:10.1149/1.2407625.

[74] N. Elgrishi, K.J. Rountree, B.D. McCarthy, E.S. Rountree, T.T. Eisenhart, J.L. Dempsey, A Practical Beginner's Guide to Cyclic Voltammetry, J. Chem. Educ. 95 (2018) 197-206. doi:10.1021/acs.jchemed.7b00361.

[75] R. Drummond, D.A. Howey, S.R. Duncan, Low-order mathematical modelling of electric double layer supercapacitors using spectral methods, J. Power Sources. 277 (2015) 317-328. doi:10.1016/j.jpowsour.2014.11.116.

[76] C. Hao, X. Wang, Y. Yin, Z. You, Modeling and Simulation of a Lithium Manganese Oxide/Activated Carbon Asymmetric Supercapacitor, J. Electron. Mater. 45 (2015) 515-526. doi:10.1007/s11664-015-4141-6. 
[77] M. Gouverneur, J. Kopp, L. Van Wüllen, M. Schönhoff, Direct determination of ionic transference numbers in ionic liquids by electrophoretic NMR, Phys. Chem. Chem. Phys. 17 (2015) 3068030686. doi:10.1039/c5cp05753a.

[78] A.P. Fröba, H. Kremer, A. Leipertz, Density, Refractive Index, Interfacial Tension, and Viscosity of Ionic Liquids [EMIM][EtSO 4 ], [EMIM] $\left[\mathrm{NTf}_{2}\right]$, [EMIM] $\left[\mathrm{N}(\mathrm{CN})_{2}\right]$, and [OMA][NTf 2$]$ in Dependence on Temperature at Atmospheric Pressure, J. Phys. Chem. B. 112 (2008) 12420-12430. doi:10.1021/jp804319a.

[79] Product Im0208a / 1-Ethyl-3-methylimidazolium bis(trifluoromethanesulfonyl)imide 99.9\%, (n.d.). http://en.solvionic.com/products/1-ethyl-3-methylimidazolium-bistrifluoromethanesulfonylimide99.9 (accessed February 22, 2019).

[80] A. Simaite, B. Tondu, P. Souères, C. Bergaud, Hybrid PVDF/PVDF-graft-PEGMA membranes for improved interface strength and lifetime of PEDOT:PSS/PVDF/ionic liquid actuators, ACS Appl. Mater. Interfaces. 7 (2015) 19966-19977. doi:10.1021/acsami.5b04578.

[81] A. Khaldi, A. Maziz, G. Alici, G.M. Spinks, E.W.H. Jager, Bottom-up microfabrication process for individually controlled conjugated polymer actuators, Sensors Actuators, B Chem. 230 (2016) 818824. doi:10.1016/j.snb.2016.02.140. 